Florida International University FIU Digital Commons

\title{
Anxiety and Callous-Unemotional Traits: Physiological and Behavioral Responses to Others' Distress
}

Kathleen I. Crum

Florida International University, kcrum001@fiu.edu

DOI: $10.25148 /$ etd.FIDC000726

Follow this and additional works at: https://digitalcommons.fiu.edu/etd

Part of the Child Psychology Commons, and the Clinical Psychology Commons

\section{Recommended Citation}

Crum, Kathleen I., "Anxiety and Callous-Unemotional Traits: Physiological and Behavioral Responses to Others' Distress" (2016). FIU Electronic Theses and Dissertations. 2599.

https://digitalcommons.fiu.edu/etd/2599 


\title{
FLORIDA INTERNATIONAL UNIVERSITY
}

Miami, Florida

\section{ANXIETY AND CALLOUS-UNEMOTIONAL TRAITS: PHYSIOLOGICAL AND BEHAVIORAL RESPONSES TO OTHERS' DISTRESS}

\author{
A dissertation submitted in partial fulfillment of \\ the requirements for the degree of \\ DOCTOR OF PHILOSOPHY \\ in \\ PSYCHOLOGY
}

by

Kathleen Isabel Crum

2016 
To: Dean Michael R. Heithaus

College of Arts, Sciences and Education

This dissertation, written by Kathleen Isabel Crum, and entitled Anxiety and CallousUnemotional Traits: Physiological and Behavioral Responses to Others' Distress, having been approved in respect to style and intellectual content, is referred to you for judgment.

We have read this dissertation and recommend that it be approved.

$\begin{array}{r}\hline \text { Stacy L. Frazier } \\ \hline \text { Maureen C. Kenny } \\ \hline \text { Erica D. Musser } \\ \hline \text { Jonathan S. Comer, Major Professor }\end{array}$

Date of Defense: July 1, 2016

The dissertation of Kathleen Isabel Crum is approved.

Dean Michael R. Heithaus

College of Arts, Sciences and Education

Andrés G. Gil

Vice President for Research and Economic Development and Dean of the University Graduate School

Florida International University, 2016 
(C) Copyright 2016 by Kathleen Isabel Crum

All rights reserved. 


\section{DEDICATIONS}

To my loving family, a team I would never trade; to my dear friend Tiffany, who crosses this finish line with me in my heart; and to everyone in the arena, wondering how much they dare to achieve. 


\section{ACKNOWLEDGMENTS}

I am immensely grateful for the support and guidance provided by mentors, committee members, colleagues, and friends throughout this process. Without my major professor, Dr. Jonathan Comer-who helped me realize my potential and taught me to never give up — and my team of dedicated research assistants, Christina Flores and Michelle Lorenzo, this project would not have been possible.

This project was generously supported by an Elizabeth Munsterberg Koppitz Fellowship in Child Psychology, awarded to Kathleen Isabel Crum by the American Psychological Foundation (APF). Study findings and conclusions are those of the author, and do not necessarily represent the views of the APF. 
ABSTRACT OF THE DISSERTATION

\title{
ANXIETY AND CALLOUS-UNEMOTIONAL TRAITS: PHYSIOLOGICAL AND BEHAVIORAL RESPONSES TO OTHERS' DISTRESS
}

\author{
by \\ Kathleen Isabel Crum \\ Florida International University, 2016 \\ Miami, Florida \\ Professor Jonathan S. Comer, Major Professor
}

Research documents considerable anxiety-related heterogeneity in youth with callousunemotional traits $(\mathrm{CU})$, a pattern of callousness and shallow emotionality (Frick \& Ellis, 1999) associated with lasting impairment (Fontaine et al., 2011). This heterogeneity may relate to behavioral differences, with the presence of both $\mathrm{CU}$ and anxiety associated with increased questionnaire-based reports of aggression and/or historical documentations of past aggression (Kahn et al., 2013). Anxiety in CU youth is associated with greater attention to others' distress cues (Kimonis et al., 2012) compared to CU-only counterparts, in contrast to the decreased distress-cue attentiveness thought to contribute to aggression in $\mathrm{CU}$ youth (Dadds et al., 2011). Through its association with improvements in CU youths' ability to detect others' distress, anxiety may heighten autonomic activity associated with emotional processing, in contrast to the dampened autonomic activity observed in CU youth (de Wied et al., 2012). It is possible that CU associations with distress-cue recognition and parasympathetic-based emotion-regulation vary as a function of anxiety, and in turn are associated with aggression. The present study, conducted with a sample of youth ages 7-13 $(N=45)$, incorporated laboratory tasks 
and self- and caregiver-report questionnaires to assess the extent to which child anxiety, traumatic stress, CU, and their interactions, predict observed aggressive behavior toward other children and perceptions of others' emotions while experimentally manipulating distress-cue salience. Exploratory analyses considered parasympathetic activity that may associate with observed relationships. Overall, results align with non-experimental research suggesting that $\mathrm{CU}$ is associated with greater aggression in the presence of anxiety (Fanti et al., 2013), and clarify that anxiety moderates the effect of CU on aggression, but only in the absence of distress cues from a potential victim. Results also hint that relationships between anxiety and parasympathetic responses to others' distress may help explain anxiety-related heterogeneity in CU youths' aggression. Findings suggest that children with $\mathrm{CU}$ and anxiety may benefit from emotional training to anticipate others' distress and identify distress cues. In aggressive situations involving these youth, increasing others' distress-cue salience may attenuate violence. Future research must further investigate emotional processing deficits, and their role in the development of aggression, among $\mathrm{CU}$ youth with anxiety. 


\section{TABLE OF CONTENTS}

CHAPTER

PAGE

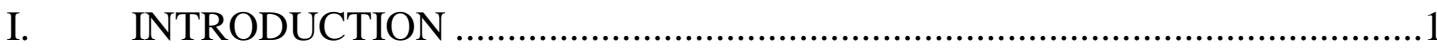

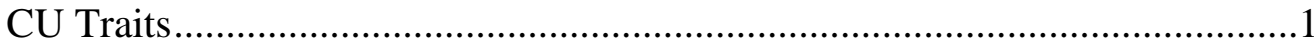

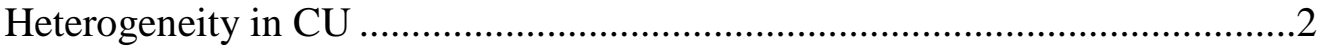

$\mathrm{CU}$ and Anxiety …………..................................................................

Anxiety and Emotional Processing in $\mathrm{CU}$........................................................5

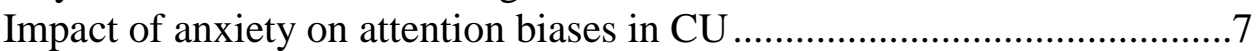

Links between anxiety and physiological response in $\mathrm{CU}$.........................8

Impact of anxiety on behavioral and physiological responses to others'

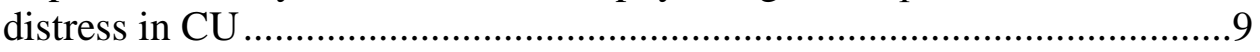

Project Aims and Hypotheses ...................................................................... 10

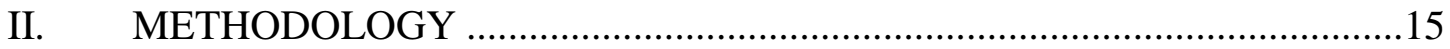

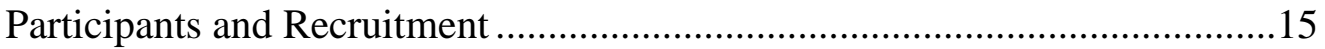

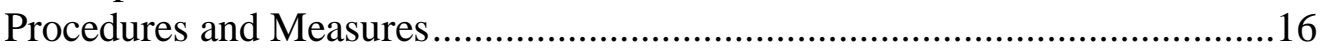

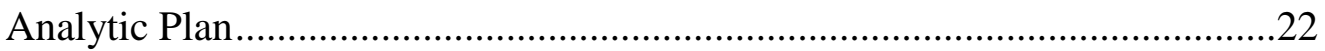

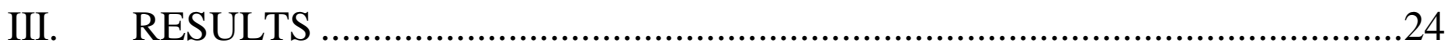

Addressing Aim Ia: Elucidating the interactive effects of CU and anxiety

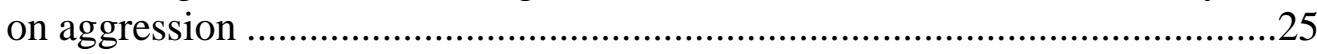

Addressing Aim Ib: Elucidating the interactive effects of CU and traumatic

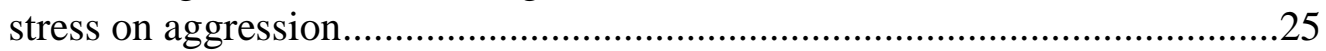

Addressing Aim IIa: Investigating the interactive effects of CU and anxiety on aggression in the presence versus absence of distress cues ....

Addressing Aim IIb: Investigating the interactive effects of CU and traumatic stress on aggression in the presence versus absence of distress

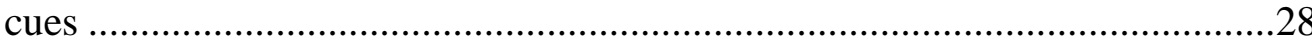

Addressing Aim IIIa: Elucidating the main and interactive effects of CU and anxiety on perceptions of a potential victim's emotional state in an

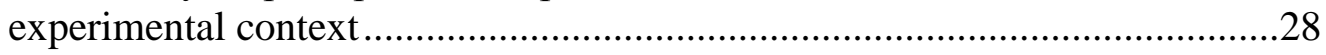

Addressing Aim IIIb: Investigating the main and interactive effects of CU and traumatic stress on perceptions of a potential victim's emotional state in an experimental context ............................................................................

Addressing Aim IVa: Elucidating the main and interactive effects of CU and anxiety on parasympathetic response to others' distress.............................31

Addressing Aim IVb: Elucidating the interactive effects of CU and traumatic stress on parasympathetic-based response to others' distress

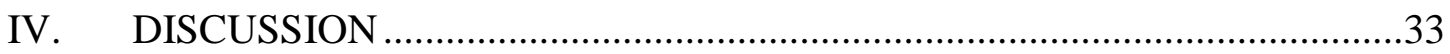

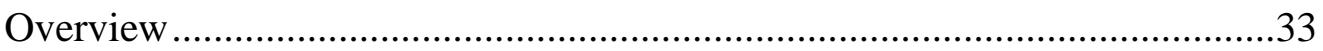

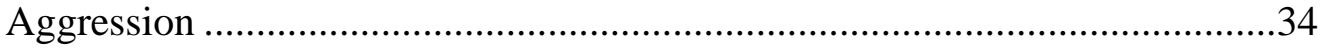

Perceptions of Peer Emotions ....................................................................... 


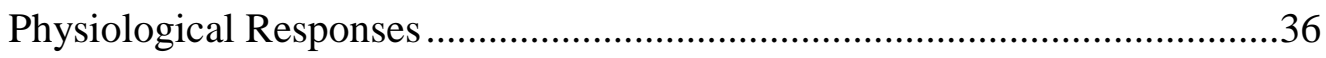

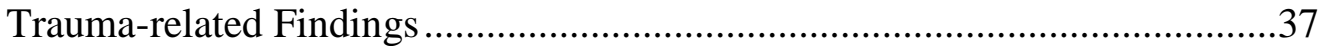

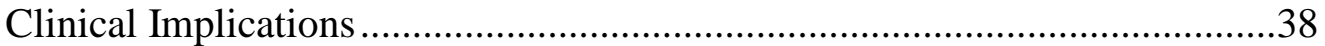

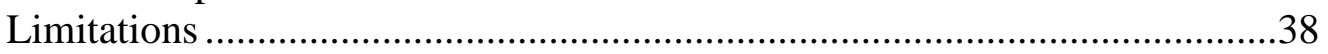

Future Directions ............................................................................4 41

Summary and Conclusions ............................................................. 41

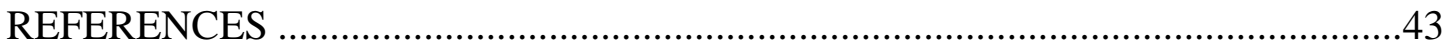

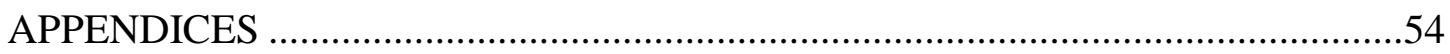

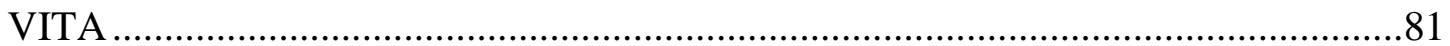




\section{LIST OF TABLES}

TABLE

PAGE

1. Descriptive statistics............................................. 58

2. Zero-order correlations between study variables..........................59

3. Coefficients for the SuperBuilder hierarchical regression models predicting aggression, with anxiety as moderator..............................60

4. Coefficients for the SuperBuilder hierarchical regression models predicting aggression, with traumatic stress as aa moderator......................61

5. Coefficients for the hierarchical regression models perceptions of simulated opponent's emotions in the absence of a distress cue, with anxiety as a moderator.

6. Coefficients for the hierarchical regression models perceptions of simulated opponent's emotions in the presence of a distress cue, with anxiety as a moderator.

7. Coefficients for the hierarchical regression models predicting changes in perceptions of simulated opponent's emotions, with anxiety as a moderator....

8. Coefficients for the hierarchical regression models perceptions of simulated opponent's emotions in the absence of a distress cue, with traumatic stress as a moderator

9. Coefficients for the hierarchical regression models perceptions of simulated opponent's emotions in the presence of a distress cue, with traumatic stress as a moderator.

10. Coefficients for the hierarchical regression models predicting changes in perceptions of simulated opponent's emotions, with traumatic stress as a moderator....

11. Coefficients for hierarchical regression models predicting parasympathetic responses, with anxiety as a moderator.

12. Coefficients for HLM predicting RSADistress scores across time, with $\mathrm{CU}$ and anxiety as moderators

13. Coefficients for hierarchical regression models predicting parasympathetic responses, with traumatic stress as a moderator. 
14. Coefficients for HLM predicting RSADistress across time, with CU and traumatic stress as moderators......................................77 


\section{LIST OF FIGURES}

FIGURE

PAGE

1. Excerpts from the SuperBuilder game play simulation. Participants were told they were building the red brick skyscraper, while their opponent was building the yellow skyscraper.....................................55

2. Explanation of SuperBuilder sound blast levels presented to the child

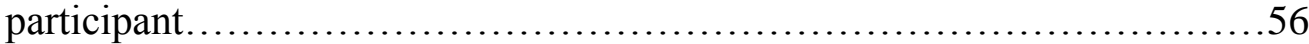

3. Neutral and distress messages, respectively, sent from the SuperBuilder simulated opponent to the child participant...........................57

4. Visual depiction of statistical models...................................78

5. Graph depicting the interactive relationship between CU and anxiety when predicting aggression in the absence of a distress cue.

6. Graph depicting the relationships between respiratory sinus arrhythmia and caregiver-reported child anxiety scores on the MASC across the five distress-condition epochs in the Distress Response task 


\section{LIST OF ACRONYMS AND ABBREVIATIONS}

American Psychiatric Association

APA

Antisocial behavior

$\mathrm{AB}$

Attention Deficit-Hyperactivity Disorder

ADHD

Callous-unemotional traits

$\mathrm{CU}$

Central nervous system

CNS

Child PTSD Symptom Scale

CPSS

Conduct problems

$\mathrm{CP}$

Electrocardiogram

EKG

Full-scale Intelligence Quotient

FSIQ2

Hierarchical linear modeling

HLM

Hostile attribution bias

$\mathrm{HAB}$

Inventory of Callous-Unemotional Traits

ICU

Lower limit of $95 \%$ confidence interval

LLCI

Medium

Med

Missing completely at random

MCAR

Multidimensional Anxiety Scale for Children, Second Edition

MASC

Parasympathetic nervous system

PNS

Peer Perception Scale

PPS

Posttraumatic Stress Disorder

PTSD

Respiratory sinus arrhythmia

RSA

Standard deviation

SD

Standard error

SE

Statistical Package for the Social Sciences

SPSS 
Upper limit of 95\% confidence interval

UCLI

Wechsler Abbreviated Scale of Intelligence, Second Edition

WASI-II 


\section{INTRODUCTION}

Research documents considerable heterogeneity in youth presenting with callousunemotional (CU) traits, a pattern characterized by callousness, shallow emotionality, and a lack of guilt following transgressions (CU; Frick \& Ellis, 1999). Empirical work suggests that anxiety-related heterogeneity in youth showing $\mathrm{CU}$ traits may be related to meaningful differences in associated aggressive behavior, with the presence of both $\mathrm{CU}$ traits and anxiety associated with a specific pattern of emotional processing deficits and higher levels of aggression than children with just CU traits (Docherty, Boxer, Huesmann, O'Brien, \& Bushman, 2015; Euler et al., 2015; Fanti, Demetrious, \& Kimonis, 2013; Humayun, Kahn, Frick, \& Viding, 2014; Kahn et al., 2013; Kimonis, Skeem, Cauffman, \& Dmitrieva, 2011; Lee, Salekin, \& Iselin, 2010; Rosan, Frick, Gottlieb, \& Fasicaru, 2015). However, much of this research has relied exclusively on questionnaire reports of aggressive behavior rather than observed aggressive behavior (e.g., Kimonis et al., 2011; Lee et al., 2010), and has not examined how anxiety and CU traits predict child aggression in the context of experimentally manipulated distress cue salience from potential victims. Much remains to be learned about the processes underlying observed associations between anxiety, CU traits, and aggressive behavior among youth in order to optimally inform taxonomy questions and intervention efforts.

\section{CU Traits}

Considerable evidence documents the occurrence of children with serious behavior problems who exhibit callousness, shallow emotionality, and a lack of guilt following transgressions (i.e., CU traits; Frick \& Ellis, 1999). Such CU traits constitute a 
profile now recognized in leading psychiatric taxonomies (e.g., American Psychiatric Association [APA], 2013), affect roughly one-third of youth with behavior problems (Christian et al., 1997), and are associated with significant social and behavioral impairment across the lifespan (Fontaine et al., 2011; Lynam et al., 2007; Obradovic, Pardini, Long, \& Loeber, 2007), and although they have been traditionally conceptualized in the context of conduct disorder, emerging empirical work supports consideration of CU traits as a transdiagnostic construct (Herpers, Rommelse, Bons, Buitelaar, \& Scheepers, 2012; Herpers, Klip, Rommelse, Greven, \& Buitelaar, 2016; Moran et al., 2009).

There is now strong evidence that children showing CU traits differ in important ways from children with behavioral problems who do not show $\mathrm{CU}$ traits, and from children without behavioral problems. For example, relative to peers, CU youth exhibit antisocial behavior $(\mathrm{AB})$ that is more severe, stable, and varied in nature (Frick, Kimonis, Dandreaux, \& Farell., 2003b; Frick \& Dantagnan, 2005), show higher levels of reactive (lashing out in response to perceived provocation) and proactive (calculated, goaldirected aggression in the absence of anger; Dodge \& Coie, 1987) aggression (Fanti, Frick, \& Georgiou, 2009; Lozier, Cardinale, VanMeter, \& Marsh, 2014; Marsh et al., 2013; Waschbusch et al., 2004), and show diminished or varied responsiveness to traditional behavioral treatments targeting AB (Hawes, Price, \& Dadds, 2014b; McDonald et al., 2011; Waschbusch et al., 2007) relative to children without CU traits.

\section{Heterogeneity in CU}

Much remains to be learned about pathways leading to AB among youth showing CU traits. Given physiological, temperamental, and cognitive differences associated with 
$\mathrm{CU}$, it has been proposed that the $\mathrm{AB}$ of children with $\mathrm{CU}$ arises from a separate pathway relative to the $\mathrm{AB}$ of children without $\mathrm{CU}$ (Frick et al., 2003a). Moreover, it is unclear whether the same mechanisms underlie $\mathrm{AB}$ development for all children with $\mathrm{CU}$, or whether multiple distinct pathways systematically eventuate in CU profiles. Through its relationship with causal pathways to $\mathrm{AB}$, heterogeneity associated with underlying processes in CU likely contributes to mixed intervention response.

\section{CU and Anxiety}

Evidence suggests that children with $\mathrm{CU}$ constitute a heterogeneous population, with some but not all susceptible to anxiety, which in turn is associated with increased dysfunction and impairment. Importantly, analogous to primary and secondary variants of psychopathy in adults (Karpman, 1948; Skeem, Poythress, Edens, Lilienfeld, \& Cale, 2003), whereas the majority of youth showing CU traits do not show elevated levels of anxiety, a subset of $\mathrm{CU}$ youth do, and elevated anxiety appears to alter the presentation of $\mathrm{CU}$ traits in several key ways. Among children with $\mathrm{CU}$, anxiety has been associated with greater questionnaire-based reports of impulsivity and externalizing behavior problems, as well as higher reports of aggression and delinquency (Kahn et al., 2013; Rosan et al., 2015; Vaughn et al., 2009), especially reactive aggression (Fanti et al., 2013), a more extensive criminal offense record (Kimonis et al., 2011), and increased reports of depressive and psychotic symptoms (Docherty et al., 2015; Vaughn et al., 2009) relative to $\mathrm{CU}$ youth without anxiety. These anxiety-related differences hold true despite comparable levels of CU traits, although some studies have noted increased (Kimonis et al., 2011; Lee et al., 2010) or decreased (Euler et al., 2015) CU trait severity among youth who show anxiety symptoms relative to CU youth without anxiety. Anxiety may interact 
with $\mathrm{CU}$ in important ways, but the nature of such interactions and their impact on youth aggressive behavior remain unclear, impeding the identification of tailored treatment targets, and hindering efforts to address the unique needs of children at various points on these continua. Moreover, and importantly, research examining interactions between $\mathrm{CU}$ and anxiety and their effects on $\mathrm{AB}$ has relied almost exclusively on questionnaire reports of child aggressive behavior (e.g., Fanti et al., 2013; Kahn et al., 2013, Rosan et al., 2015), and the studies that used criminal records did not assess aggression in an experimental context (e.g., Kimonis et al., 2011; Lee et al., 2010), which limits interpretations and cannot rule out issues related to reporter biases, shared method variance, and external circumstances.

Of note, several studies have observed greater trauma exposure among $\mathrm{CU}$ youth experiencing anxiety symptoms relative to their counterparts without anxiety (Euler et al., 2015; Kahn et al., 2013; Kimonis et al., 2012; Tatar et al., 2012). Trauma is central to theory underlying origins of primary and secondary variants in psychopathy (e.g., Porter, 1996), and may be a particularly relevant factor in the affective and behavioral characteristics of children with $\mathrm{CU}$ and anxiety, considering research suggesting that traumatic stress-related emotional numbing symptoms link violence exposure and delinquency (Allwood, Bell, \& Horan, 2011), and often co-occur with hypervigilance/hyperarousal symptoms (Weems, Saltzman, Reiss, \& Carrion, 2003). Furthermore, trauma-exposed youth show a specific pattern of emotional processing abnormalities, including an attentional bias towards threat (Dalgleish, Moradi, Taghavi, Neshat-Doost, \& Yule, 2001), enhanced identification of fearful faces (Masten et al., 2008), and heightened sympathetic nervous system activity (see Teicher, Andersen, 
Polcari, Anderson, \& Navalta, 2002). It is worthwhile to assess the degree to which the aggressive reactivity and internalizing symptoms (e.g., Docherty et al., 2015; Fanti et al., 2013) reported by CU youth experiencing anxiety symptoms may actually represent traumatic stress symptoms. Thus far, trauma exposure and traumatic stress symptoms have been examined as clinical correlates differentiating variants of CU youth with respect to anxiety (e.g., Humayun et al., 2013; Kimonis et al., 2012); the potential for traumatic stress to moderate the link between $\mathrm{CU}$ and observed aggression in the context of experimentally manipulated distress cues has not been explored.

\section{Anxiety and Emotional Processing in CU}

Anxiety-related variations in CU presentation may be a result of differences in emotional processing across affected youth, as deficits in emotional processing are thought to facilitate the development of $\mathrm{AB}$, including aggression, in $\mathrm{CU}$ youth (Blair et al., 2006). Child CU traits are associated with deficits in distress cue detection and recognition, as well as emotional responding (e.g., Blair et al., 2005; Muñoz, 2009; Woodworth \& Waschbusch, 2008) that are susceptible to correction via increases in distress cue salience (Dadds et al., 2006; Dadds, El Masry, Wimalaweera, \& Guastella, 2008; van Baardewijk et al., 2009). Child CU traits have also been associated with deficits in physiological reactions to distress-related cues as indexed by correlates of parasympathetic and sympathetic activity, an important factor in emotional responding (e.g., Blair et al., 2005; de Wied, van Boxtel, Matthys, \& Meeus, 2012). These deficits in recognizing and responding to others' emotions correspond with reported deficiencies in cognitive and affective empathy (e.g., Dadds et al., 2009) — the ability to identify and match others' emotional states, respectively (see Hoffman, 1984). 
Attention to, and interpretation of, others' emotions influences affective matching of emotional states and, ultimately, emotional responding (Eisenberg et al., 2009; 2010). In addition to deficiencies in cognitive empathy— that is, accurately identifying others' distress-related emotions (Eisenberg \& Fabes, 1990; Hoffman, 1984)—CU youth show a pattern of hostile social cognition (see Frick, Ray, Thornton, \& Kahn, 2014 for a review). Youth with CU traits downplay the effects of their aggression on victims in hypothetical conflict situations, reporting less concern for victims' suffering, and endorsing social goals focused on dominance and forced respect (Pardini, 2011; Pardini \& Byrd, 2012). When children with CU experience anxiety symptoms, they may be particularly at risk for difficulties accurately identifying others' emotions, as anxiety is associated with its own unique pattern of social-cognitive biases, including biased attention towards threatrelated stimuli (Taghavi, Moradi, \& Neshat-Doost, Yule, \& Dalgleish, 2000) and a tendency to interpret neutral stimuli as negative or threatening (Reid, Salmon, \& Lovibond, 2006). Although Kimonis and colleagues (2012) examined attention to distress cues among children with $\mathrm{CU}$ and anxiety using distressing pictures in a dot-probe task, the extant literature on anxiety in children with CU traits has not investigated perceptions of peer emotion in experimental tasks approximating social interactions.

Understanding these emotional deficits is essential to prevention of $\mathrm{AB}$ among children with CU traits, and research has shown the importance of potential victims' distress cue salience in reducing emotion recognition deficits and altering aggressive behavior in CU youth. Increased salience of others' emotional cues has been linked to increased accuracy of emotion recognition among CU youth, perhaps as a function of attention to distress cues (Dadds et al., 2012). Indeed, when children are specifically 
instructed to attend to emotional cues indicating others' distress, and when distress cue salience itself is increased (Blair, Colledge, Murray, \& Mitchell, 2001), discrepancies in distress-related emotion recognition between youth with and without $\mathrm{CU}$ traits are reduced (Dadds et al., 2008). Increases in others' distress cue salience have also been associated with a decrease in the strength of the relationship between CU traits and aggression (van Baardewijk et al., 2009). However, it remains unclear how anxiety-based heterogeneity may affect associations between CU, aggression, others' distress cue salience, and physiological and behavioral responses to others' emotions, as well as perceptions of others' emotions.

\section{Impact of anxiety on attention biases in $\mathrm{CU}$.}

By signaling the potential for a variety of links between emotional processing and CU traits, anxiety-based differences in attention to others' distress cues may have important implications for understanding links between $\mathrm{CU}$ and aggressive behavior, and for developing informed treatment targets. Indeed, evidence suggests that anxiety in CU youth alters emotional processing, and points to variation in the processes underlying the cognitive, temperamental, and behavioral styles typical to CU traits. Among youth with high levels of CU, anxiety is associated with greater attention to others' distress cues (Kimonis, Frick, Cauffman, Goldweber, \& Skeem, 2012) than CU-only counterparts, in contrast to the decreased attentiveness to these cues thought to contribute to $\mathrm{AB}$ in $\mathrm{CU}$ youth (Dadds et al., 2011). Only one existing study has examined attention to others' distress cues as a function of CU and anxiety (Kimonis et al., 2012), and while Kimonis and colleagues' findings provide preliminary information on patterns of emotional deficits among CU youth, further research incorporating observational paradigms is 
needed to examine how such anxiety-CU interaction patterns may influence corresponding behavioral heterogeneity.

\section{Links between anxiety and physiological response in $\mathrm{CU}$.}

Attentional differences accompanying anxiety in children with $\mathrm{CU}$ may be directly associated with corresponding differences in physiological processes, which may in turn affect clinical presentation and intervention response. Despite the lack of research in this area, anxiety in CU youth may result in distinct physiological profiles in response to others' distress. As anxiety is associated with improvements in the ability of CU youth to detect others' distress cues (Kimonis et al., 2012), anxiety may indirectly heighten related autonomic activity associated with emotional processing, in contrast to the dampened parasympathetic and sympathetic activity typically observed in CU youth (e.g., Anastassiou-Hadjicharalambous \& Warden, 2008b; Blair, 1999; de Wied et al., 2012; Muñoz, Frick, Kimonis, \& Aucoin, 2008). Further, neural abnormalities in the form of limited amygdala function (e.g., Blair et al., 2006; Jones, Laurens, Herba, Barker, \& Viding, 2009; Lozier et al., 2014) are associated with the "fearlessness" commonly ascribed to youth with high levels of CU (e.g., Pardini, 2006). Fearlessness is contradictory, however, to the worry and fears associated with chronic, trait-like anxiety in youth with CU (e.g., Fanti et al., 2013). It may be that anxiety lessens these CU-related abnormalities, reducing the blunted parasympathetic and sympathetic activity observed in non-anxious children with CU traits. Thus far, no research has explored relationships between CU, anxiety, and physiological response to others' distress. 


\section{Impact of anxiety on behavioral and physiological responses to others' distress in}

CU.

Considering the potential and observed alterations in emotional processing associated with anxiety in children with $\mathrm{CU}$, it is possible that $\mathrm{CU}$ associations with distress cue recognition and with physiological correlates of emotional response and regulation vary as a function of anxiety, and in turn are associated with aggressive behavior in important ways. Emotional processing and physiological correlates appear to play a central role in driving behavioral responses to fear or distress in other individuals. Indeed, accurate emotion identification and optimal levels of affective arousalfacilitated by matching of affective states - are required to elicit prosocial responses to others' distress such that a lack of affective arousal — that is, an affective response to others' distress, thought to be facilitated by physiological activity-precludes prosocial behavior (Eisenberg \& Fabes, 1990; Eisenberg et al., 2010). On the other hand, overly high levels of affective arousal are associated with personal distress, which may even encourage aggressive behavior towards the perceived cause of distress, or withdrawal from the distressing stimulus (Eisenberg \& Eggum, 2009; Eisenberg et al., 2010). If anxiety enables children with CU to attend to and recognize others' distress more easily, or enables children with CU to experience heightened physiological response to others' distress, differences in behavior should be apparent; however, the manner in which differences in emotional processing associated with anxiety are linked to aggressive behavior is thus far unexamined. Importantly, existing research on relationships between $\mathrm{CU}$, anxiety, and aggression has relied almost exclusively on questionnaire measures, rather than observed measures of aggression (e.g., Rosan et al., 2015), and no existing 
research has examined these relationships in an experimental context; thus the complex interplays between these factors remain unclear.

Improved understanding of the potential pathways by which emotional processing is linked to aggression among children with $\mathrm{CU}$ and anxiety may lie in investigating the role of distress cue salience (e.g., Kimonis et al., 2012). By intensifying others' emotional cues and reducing their ambiguity, increases in the salience of distress cues may influence the manifestation of aggression among children with CU and anxiety. Experimental manipulation of distress cues in the context of social interaction is needed to clarify the role of emotional processing in the heightened aggression documented in children with CU and anxiety. Given this theoretical and empirical background, it is possible that anxiety significantly alters the relationship between $\mathrm{CU}$ and empathy-related responding, shaping underlying processes that contribute to behavioral and social impairment.

\section{Project Aims and Hypotheses}

The overall goal of this work is to examine the complex interplays between child CU and anxiety in predicting aggressive behavior, to examine how the salience of others' distress cues affects links between CU, anxiety, and aggression, and to consider physiological processes - specifically, parasympathetic activity associated with emotion regulation - that may correlate with such associations. The research incorporated an experimental manipulation in a sample of youth ages 7 to $13(N=45)$, incorporating laboratory tasks and self- and caregiver-report questionnaires to assess the extent to which child anxiety, traumatic stress symptoms, CU traits, and their interactions, predict observed aggressive behavior toward other children and perceptions of others' emotions 
while experimentally manipulating the salience of distress cues from the other child. Observations of aggressive behavior were collected in the context of a competitive game simulation in which, unbeknownst to participating youth, the opponent child against whom participants could aggress was in fact a programmed computer simulation. Exploratory analyses further considered parasympathetic functioning and regulation that may associate with observed relationships. By enhancing the field's understanding of anxiety-related heterogeneity and its interaction with $\mathrm{CU}$, and examining the intricate relationships between underlying attentional and physiological processes and aggression in children, the current study can meaningfully advance theoretical models of $\mathrm{CU}$ and lay an empirical foundation for targeted treatment development. Further, the current study can lay the groundwork for future translational investigations of physiological processes mediating emotional processing abnormalities in $\mathrm{CU}$ youth.

-Aim Ia: Elucidate the interactive effects of CU and anxiety on behaviorally observed aggression in an experimental context. Hypothesis: Given the growing body of literature documenting a subset of children with CU traits who show significant anxiety and increased questionnaire-based reports of aggression (e.g., Docherty et al., 2015, Rosan et al., 2015) and more extensive criminal records (Kimonis et al., 2011), it was hypothesized that child anxiety will moderate the impact of CU severity on behaviorally observed aggression (regardless of distress cue salience), such that higher levels of child anxiety would be associated with a stronger link between $\mathrm{CU}$ and observed aggression.

-Aim Ib: Elucidate the interactive effects of CU and traumatic stress symptoms on behaviorally observed aggression. Hypotheses: Given research documenting more extensive trauma histories among children with $\mathrm{CU}$ and anxiety than their CU-only 
counterparts (e.g., Euler et al., 2015), along with literature indicating potential overlap between callousness and posttraumatic emotional numbing symptoms (Allwood et al., 2011), it was hypothesized that among trauma-exposed youth, traumatic stress symptom severity will moderate the impact of CU severity on behaviorally observed aggression (regardless of distress cue salience), such that higher levels of traumatic stress would be associated with a stronger link between $\mathrm{CU}$ and observed aggression.

-Aim IIa: Investigate the extent to which the interactive effects of CU and anxiety on observed aggression vary relative to the salience of a potential victim's distress. Hypotheses: It was expected that CU severity would be strongly associated with observed aggression when the salience of a potential victim's distress is manipulated to be absent, but would not be associated with observed aggression when the potential victim's distress was manipulated to be salient (van Baardewijk et al., 2009). It was expected that the predictive value of the interaction between CU and anxiety would differ in the presence versus absence of others' distress cues, given the unique pattern of emotional deficits observed among youth with CU and anxiety (Kimonis et al., 2012).

-Aim IIb: Investigate the extent to which the interactive effects of CU and traumatic stress symptoms on observed aggression vary relative to the salience of a potential victim's distress. Hypotheses: It was expected that the predictive value of the interaction between $\mathrm{CU}$ and traumatic stress symptoms would differ in the presence versus absence of others' distress cues, given the trauma histories reported among youth with CU and anxiety (e.g., Kahn et al., 2013), and the emotional deficits observed among youth with posttraumatic stress (e.g., Dalgleish et al., 2001; Masten et al., 2008). 
-Aim IIIa: Elucidate the main and interactive effects of CU and anxiety on perceptions of a potential victim's emotional state in an experimental context.

Hypothesis: Given research documenting reductions in emotion recognition deficits (e.g., Dadds et al., 2006) with increased distress cue salience among CU youth, it was expected that CU severity would not be associated with ratings of the simulated opponent's affect ratings in the absence of a distress cue, but that in the presence of a distress cue, CU severity would be associated with increased ratings of the simulated opponent's negative affect, and decreased ratings of the simulated opponent's neutral and positive affect. It was further expected that anxiety would moderate the effect of CU severity on ratings of the simulated opponent's distress-related emotions. Specifically, it was predicted that higher levels of child anxiety would be associated with a stronger link between CU and ratings indicating the simulated opponent's negative affect, such that greater anxiety was associated with higher ratings of these emotions, given literature indicating increased attention to distress cues (Kimonis et al., 2012) among children with CU and anxiety. It was also expected that CU severity would be associated with changes in ratings of the opponent's negative affect, but that anxiety would moderate the effect of CU severity on such changes. Specifically, it was predicted that higher levels of child anxiety would be associated with a stronger link between CU and changes in perceptions of opponents' negative affect, given the increased attention to distress cues (Kimonis et al., 2012) observed among children with CU and anxiety.

-Aim IIIb: Investigate the main and interactive effects of CU and traumatic stress on perceptions of a potential victim's emotional state in an experimental context.

Hypothesis: Given literature documenting enhanced identification of fearful faces among 
trauma-exposed youth (Masten et al., 2008), it was expected that traumatic stress would moderate the effect of CU severity on ratings of the simulated opponent's negative affect. Specifically, it was predicted that higher levels of child traumatic stress would be associated with a stronger link between CU and ratings of the simulated opponent's negative affect, such that greater traumatic stress was associated with higher ratings of these emotions. It was also expected that child traumatic stress would moderate the effect of CU severity on changes in ratings of the opponent's negative affect, such that higher levels of traumatic stress would be associated with a stronger link between CU and changes in perceptions of opponents' negative affect, given literature linking child traumatic stress to enhanced identification of others' fear-related cues (Masten et al., 2008).

-Aim IVa: Elucidate the interactive effects of CU and anxiety on parasympathetic-based regulation in response to others' distress. Hypothesis: It was expected that CU will be associated with blunted parasympathetic response to others' distress similar to previous findings (e.g., Anastassiou-Hadjicharalambous \& Warden, 2008b; de Wied et al., 2012), but that anxiety would alter this relationship by increasing parasympathetic response to this stimulus, given that anxiety has been associated with increased attention to distress cues among CU youth (Kimonis et al., 2012).

-Aim IVb: Elucidate the interactive effects of CU and traumatic stress on parasympathetic response to others' distress. Hypothesis: It was expected that traumatic stress would alter the relationship between CU and blunted parasympathetic regulation by increasing parasympathetic response to others' distress, given that traumatic stress has been associated with both increased attention to distress cues (e.g., Masten et al., 2008) - 
an emotional processing pattern observed among CU youth (Kimonis et al., 2012) — and heightened autonomic activity (Teicher et al., 2002).

Gaining a better understanding of the relationships between child anxiety,

traumatic stress, $\mathrm{CU}$, and observed aggressive behavior in the context of experimentally manipulated distress cue salience is critical to informing individualized treatment strategies and offsetting future difficulties. As a whole, these efforts can contribute valuable information to assessment and intervention science, reducing the heavy burden that $\mathrm{CU}$ places on affected individuals, their families, and society at large.

\section{METHODOLOGY}

\section{Participants and Recruitment}

All study activities were approved by the Florida International University Institutional Research Board. A conduct problems (CP)-enhanced community sample was recruited, given the relatively low rate of $\mathrm{CU}$ in the general community (Rowe et al., 2010). Specifically, community recruitment of youth included — in addition to broad school-based and flyer-based recruitment—strategic recruitment outreach at clinics offering behavioral treatments for child behavior problems. Phone screens were administered to interested caregivers of potential participants to assess whether children met the following eligibility criteria: 1) age of seven to thirteen years, inclusive; 2) no reported history of autism spectrum disorder or severe mental or physical impairments (e.g., intellectual disability, deafness, blindness); and 3) no current psychotropic treatment, except for stimulant medications which could be easily discontinued for study participation. Eligible families were invited to a laboratory visit to complete the following: 1) informed consent and assent, 2) child laboratory tasks and rating scales, and 
3) caregiver rating scales. Prior to the visit, families of children taking stimulant medication were asked to forgo medication administration for a 48-hour washout period. This period is considered sufficient to preclude stimulant medication effects on tasks (Greenhill et al., 2001), and has been used in previous research on children's cognitive task performance (e.g., Wilson, Mitchell, Musser, Schmitt, \& Nigg, 2011).

Participants were 45 children between the ages of seven and thirteen $(M=9.89$, $S D=1.58 ; 71.1 \%$ boys, $28.9 \%$ girls) and their caregivers. Caregivers $(90.9 \%$ mothers, $6.8 \%$ fathers, $2.3 \%$ grandmothers) reported on child participants' emotions and behavior, as well as demographic information. Regarding race/ethnicity, per caregiver report, 75.6\% of child participants were Hispanic, $13.3 \%$ were non-Hispanic White, and $11.1 \%$ were non-Hispanic Black. Among families for whom income was reported, 50\% of caregivers reported an annual income of $\$ 48,000$ or lower, $25 \%$ of caregivers reported an income between $\$ 50,000$ and $\$ 97,000$, and $25 \%$ of caregivers reported an annual income of $\$ 100,000$ or higher. Children recruited from clinics showed no differences from children recruited from other community sources with regard to gender $\left(\chi^{2}(1)=0.65\right.$, $p=.42)$, race/ethnicity $\left(\chi^{2}(2)=1.38, p=.50\right)$, age $(t(43)=-0.33, p=74)$ and household income $(t(34)=0.13, p=.90)$.

\section{Procedures and Measures}

During the laboratory visit, informed consent and assent was obtained from caregivers and child participants, respectively. Next, caregivers completed questionnaires on children's emotion and behavioral characteristics, while children participated in several experimental tasks and completed self-report questionnaires. Two laboratory tasks were used to measure child responses to others' distress, and task order was 
counterbalanced to control for any potential task sequence effects. The order in which the laboratory tasks were administered was chosen using a counterbalance sheet, such that the task order was reversed from the preceding participating, allowing approximately $50 \%$ of children to participate in one task first, and $50 \%$ of children to participate in the other task first. Following participation in the laboratory tasks, an intelligence test was administered to child participants, and then children completed self-report questionnaires. Lastly, children were de-briefed on the use of deception (as described below) in the laboratory tasks. Caregivers were compensated with a \$25 gift card, and children received a toy, following completion of all study activities and measures.

Child callous-unemotional traits. Caregiver ratings on the Inventory of Callous Unemotional Traits (ICU; Essau, Sasagawa, \& Frick, 2006) were used to measure child CU traits. The ICU is a well-established measure of CU traits in this age group, and is comprised of 24 items rated on a scale from 0 ("Not at all true") to 3 ("Definitely true"). Using the original scoring, Kimonis, Fanti, and Singh (2014) found children with a parent-rated ICU total score of 24 or above would benefit from services tailored towards CU traits. Numerous studies support the reliability and validity of the ICU, particularly in distinguishing between CP behaviors and CU (e.g., Fanti et al., 2009; Kimonis et al., 2008; Kimonis et al., 2014; Roose et al., 2009). Hawes and colleagues (2014a) used exploratory factor analysis to identify an alternative scoring method that improved the psychometric properties of the measure. Total scores obtained using Hawes' et al.'s alternative scoring method were used in the present analyses. Internal consistency was acceptable in the current sample $(\alpha=.81)$. 
Child anxiety. Child anxiety was measured by caregiver ratings on the Multidimensional Anxiety Scale for Children, Second Edition (MASC; March, Parker, Sullivan, Stallings, \& Conners, 1997; March, 2013). The MASC is comprised of 39 items on a scale from 0 ("Never true about me") to 3 ("Often true about me"). The MASC assesses several domains of anxiety that are summed to yield a total anxiety score. The test-retest reliability and predictive validity of the MASC have been demonstrated by past research (e.g., Muris, Merckelbach, Ollendick, King, \& Bogie, 2002; Wei et al., 2014). Internal consistency was very strong in the current sample $(\alpha=.92)$.

Prior child trauma exposure and posttraumatic stress symptoms. In keeping with previous studies exploring the role of anxiety in CU (e.g., Kimonis et al., 2012), children completed a self-report measure of trauma exposure and corresponding posttraumatic stress symptoms. The Child PTSD Symptom Scale (CPSS; Foa et al., 2001) was used to measure child posttraumatic stress symptoms. First, children were administered a preliminary trauma exposure questionnaire. A list of the following potentially traumatic events was provided: a) anything really terrible or upsetting, like being very sick or badly hurt; b) seen anyone die or badly hurt; c) been in a really bad accident or fire where you could have died; d) been in anything like a really bad hurricane, flood, or earthquake or had a tornado near where you lived; e) been robbed or attacked; f) been touched on parts of your body that you really didn't want to be touched; g) been made to touch someone else in places that you didn't want to; h) been hit over and over or hurt very badly by someone; i) anything else that someone has done to you, or made you do, that you didn't like. Children were asked to select "Yes" or "No" if they had experienced any of these events (regardless of which, or how many, events they had 
experienced). If children selected "Yes," they were asked to complete the CPSS. The CPSS is composed of 17 symptom-severity items rated from 0 ("Not at all or only at one time") to 3 ("5 or more times a week/almost always"), and 7 impairment "Yes" or "No" items. The symptom severity items comprise several subscales—including reexperiencing, avoidance, and hyperarousal — that are summed to create a total score. The test-retest reliability and construct validity of the CPSS have been demonstrated in past research (Foa et al., 2001; Gillihan, Aderka, Conklin, Capaldi, \& Foa, 2013; Nixon et al., 2013). Internal consistency of the CPSS was very strong in the current sample for the symptom-severity ( $\alpha=.92)$ items.

Child distress-response. The distress-response task was designed to assess parasympathetic nervous system (PNS) regulation of physiological arousal in response to the distress of others. Respiratory sinus arrhythmia (RSA; the high-frequency component of the heart-rate variability spectrum) is an indicator of PNS regulation of physiological arousal (Hayano et al., 2001; Appelhans \& Luecken, 2006). During the task, children were seated in a comfortable chair and connected to psychophysiological equipment. Specifically, heart rate was measured using EKG leads applied to the upper right clavicle and lower left rib, as well as a grounding electrode on the lower right rib. Impedance cardiography allowed assessment of RSA and respiration using four electrodes. One electrode was applied over the clavicle close to the neck, and another electrode was applied to the back of the neck in a corresponding location. Additionally, one electrode was applied over the xiphoid process, with another electrode applied to a corresponding location over the spine. 
Child participants were told they would listen to two recordings, including one recording of nature sounds, and one recording of another child who was very upset. Initial recording occurred for five minutes, during which a relaxation soundtrack was played, to establish a resting baseline. Immediately following the relaxation soundtrack audio recording, a five-minute audio recording of a distressed child crying was played. Data collection and analysis occurred through equipment and software from MindWare Technologies, Ltd. (Gahanna, OH). Respiration and heart rate were used to calculate heart-rate variability, from which RSA was assessed using spectral analysis. Lower resting RSA and parasympathetic-based regulation in response to distress cues reflects reduced parasympathetic activity, a response observed in $\mathrm{CU}$ youth in comparison to youth with behavior problems and healthy controls (Anastassiou-Hadjicharalambous \& Warden, 2008b; de Wied et al., 2012) and ADHD youth with low prosocial behavior, a proxy for CU traits (Musser, Galloway-Long, Frick, \& Nigg, 2013), in comparison to ADHD youth without low prosocial behavior. Given high correlations across RSAResting epochs ( $r \mathrm{~s}=.68-.90)$ and RSA $A_{\text {DistressExposure }}$ epochs $(r=.78-.90), \mathrm{RSA}_{\mathrm{Resting}}$ was calculated by averaging RSA across the five 60-second epochs of data collection during the relaxation phase, and RSADistressExposure was calculated by averaging RSA across the five 60 -second epochs of data collection during the distress phase. $\mathrm{RSA}_{\text {Reactivity }}$ was calculated by subtracting RSA $A_{\text {DistressExposure }}$ from RSAResting.

Child aggression. Aggression assessment consisted of a game simulation task (SuperBuilder) modeled after the FastKid! task developed by Thomaes and colleagues (2008), and a well-validated protocol used in adults with psychopathy (Giancola \& Zeichner, 1995). The task was designed for the present study to offer a standardized and 
observational assessment of aggression, as well as changes in aggression with respect to experimentally manipulated distress cue salience. Participants were told they were going to play a computer game against another child situated out of sight in a nearby room. In reality, the experimenter controlled all events, and there was no real child opponent. Prior to the game, children were told that the goal of the game was to press a specific keyboard button very quickly to construct buildings at a faster rate than their "opponent", and that there are two rounds with several trials each. First- and third-round winners earned the opportunity to send the opponent a text message. Second- and fourth-round winners earned the opportunity to "blast" the opponent with white noise. The "opponent" was rigged to win the first and third round. Figures $1-3$ present several screen shots from the computer task.

Distress cue salience was manipulated within subjects, with participants receiving a neutral text message from the competitor following the first round (i.e., "This game is crazy fast! \#JustDoIt" accompanied by a neutral emoticon), and a text message expressing distress following the third round (i.e., "Super worried about that blast!" accompanied by a sad emoticon). To ensure that child participants were able to read the message received from their fictitious opponent, participating youth were asked to read each message aloud immediately following receipt. Participants were rigged to win the second and fourth round, were given an example of the noise they could use against their opponent, with intensities ranging from no noise (level 0) to $100 \mathrm{~dB}$ (level 10; intensity of a smoke alarm), and were told that levels 7 and above are extremely loud. Observed aggression was measured by noise levels chosen; noise levels from round 2 represent child aggression in the absence of a distress cue, noise levels from round 4 represent 
aggression in the presence of a distress cue, and the sum of these noise levels represents total observed aggression. Participants entered noise levels chosen using the keyboard, and typed responses were recorded directly into a document. The first response typed was considered the noise level chosen. Immediately following their entry, children were asked to confirm the noise level they chosen; each child accurately related his or her typed choice $(r=1.00, p<.001)$.

Following each round of SuperBuilder, children were administered a peer perception scale (PPS), in which they rated their perceptions of the intensity of emotions (i.e., sad, scared, angry, calm, happy) experienced by the fictitious competitor on a scale from 0 ("Not at all") to 4 ("Extremely").

Child intelligence. The Wechsler Abbreviated Scale of Intelligence, Second Edition (WASI-II; Wechsler, 1999; 2011) was used to measure children's intelligence. While the instrument is comprised of four subtests-Block Design, Vocabulary, Matrix Reasoning, and Similarities, a full-scale IQ (FSIQ2) may be calculated using the Matrix Reasoning and Vocabulary subtests. The factor structure and validity of the WASI have been supported (Canivez, Konold, Collins, \& Wilson, 2009; Sakolfske, Caravan, \& Schwartz, 2000).

\section{Analytic Plan}

Means, SDs, and zero-order correlations among study variables were first computed. A check was conducted examining the success of tasks' manipulation of others' distress salience. Paired-samples t-tests were conducted examining differences between the distress and no distress salience conditions with regard to participant reports on the PPS of how "calm," "happy," "angry," "sad," and "scared" their opponent was. 
Regression techniques were used to assess relationships between CU, anxiety, and physiological, as well as behavioral, responses to others' distress. Prior to conducting the main analyses, data were checked for normality and other assumptions of regression models; given the skewed distribution of several study variables and sample size, bootstrap estimations of population distributions were used to increase confidence in results (Efron, 1979; Efron \& Tibshirani, 1993). Bootstrapping resampling techniques produce robust standard errors and confidence interval estimates when assumptions of regression are not met (Bollen \& Stine, 1990; Russel \& Dean, 2000).

Hierarchical linear regression models were used to assess moderation for study Aims I-III. Figure 4 depicts the analytical models examined to predict aggression, changes in child ratings of peer emotions between the neutral and distress messages, and parasympathetic responses to distress. Moderation analyses were conducted using the PROCESS macro for SPSS (Hayes, 2012). For each model predicting behavioral or parasympathetic response outcomes, the main effects of child CU traits and anxiety were entered, as well as the product term of CU traits and anxiety; parallel models were created by entering the main effects of child CU traits and traumatic stress, as well as the product term of CU traits and traumatic stress. Significant moderation is defined by a significant interaction (product) term of the predictor (CU traits) and proposed moderator (anxiety or traumatic stress) after accounting for main effects (Baron \& Kenny, 1986; Holmbeck, 1997; Kendall \& Comer, 2011). In bootstrapped regression, 95\% biascorrected confidence intervals, rather than $p$-values, are used to assess significance; specifically, the null hypothesis is rejected if zero does not fall within the confidence interval (Rasmussen, 1987). Variables were mean-centered prior to entry in analyses. 
Additional moderation analyses predicting parasympathetic responses further examined whether clinical characteristics differentially predicted participants' parasympathetic responses to others' distress unfolding across time. Specifically, hierarchical linear modeling (HLM) was used to examine whether CU, anxiety, traumatic stress, and their interactions predicted changes in RSA $A_{\text {Distress }}$ across time during prolonged exposure to others distress. Separate, parallel models predicting RSA Distress across the 5 individual distress-condition epochs (i.e., RSA $A_{\text {Distress }}$ through $\mathrm{RSA}_{\text {Distress5) were created }}$ for anxiety and traumatic stress moderators, such that time, $\mathrm{CU}$, anxiety, and their interactions were entered as predictors in one model, and time, $\mathrm{CU}$, traumatic stress, and their interactions were entered as predictors in a second model. RSAResting was entered as a covariate in both models.

Missing values analyses found no significant differences among participants with and without missing data on study variables, suggesting that data were missing completely at random, $\chi^{2}(168)=190.75, p=.11$ (MCAR; Little \& Rubin, 1987). Given the random nature and small overall percentage $(1.7 \%)$ of missing data, listwise deletion was used to handle missing observations.

\section{RESULTS}

Table 1 presents descriptive data for study variables and participant demographics. Nearly half $(45.5 \%, \mathrm{~N}=20)$ of this $\mathrm{CP}$-enhanced community sample showed significant CU traits according to Kimonis and colleagues' (2014) criteria (i.e., ICU $\geq 24)$. Roughly $31 \%(\mathrm{~N}=14)$ of the sample showed anxiety in the high-average range or above (i.e., MASC $t$ score $\geq 55$ ), with approximately $20 \%$ ( $\mathrm{N}=9$ ) showing clinically elevated anxiety (i.e., MASC $t$ score $\geq 60$; March, 2013). With regard to trauma, 55.6\% 
$(\mathrm{N}=25)$ of the sample experienced a traumatic event; of these children, approximately $31 \%(\mathrm{~N}=14)$ met symptom severity criteria for PTSD (Foa et al., 2001; Hawkins \& Radcliffe, 2006).

Youth were fairly aggressive overall, with only $4.4 \%(\mathrm{~N}=2)$ of children choosing not to aggress against their opponent at all following receipt of the neutral message, and only $8.9 \%(\mathrm{~N}=4)$ choosing not to aggress against their opponent at all following receipt of the distress message. Roughly $71 \%(\mathrm{~N}=32)$ of youth delivered a "blast" at level 7 or above, which was explained to the participants as "extremely loud" during the game instructions; this percentage remained the same following receipt of both neutral and distress messages from the opponent. The number of children selecting the highest blast-level 10 -increased from 23 (approximately 51\%) following receipt of a neutral message to $27(60 \%)$ following receipt of a distress message. Table 2 provides zero-order correlations for main study variables.

Manipulation checks indicated the task was successful in manipulating the salience of the opponent distress. A paired-samples t-tests manipulation check revealed children's ratings of how "scared" and "sad" they perceived their opponent to be indeed increased from the no distress/neutral message condition to the distress salience condition $(t(43)=7.75, p<.001, t(43)=5.03, p<.001$, respectively). Children's ratings of how "angry" they perceived their opponent to be also increased from the no distress/neutral message condition to the distress salience condition $(t(43)=5.90, p<.001)$. Similarly, children's ratings of how "calm" and "happy" they perceived their opponent to be decreased from the no distress/neutral message condition to the distress salience condition $(t(42)=-2.50$, $p=.02, t(43)=-7.37, p<.001$, respectively). 


\section{Addressing Aim Ia: Elucidating the interactive effects of $\mathrm{CU}$ and anxiety on}

aggression

Table 3 presents results from hierarchical regression analyses examining the main and interactive effects of CU traits and anxiety on total observed child aggression exhibited during the SuperBuilder game. The overall model was significant in the

prediction of total aggression pooled across the two conditions, $F(3,40)=3.03, p=.04 ; \mathrm{R}^{2}$ $=0.18$. However, neither CU traits nor anxiety significantly predicted total aggression pooled across the two conditions. Similarly, the product term examining the interactive effect between CU traits and anxiety did not significantly predict total aggression pooled across the two conditions.

\section{Addressing Aim Ib: Elucidating the interactive effects of $\mathrm{CU}$ and traumatic stress on aggression}

Table 4 presents results from hierarchical regression analyses examining the main and interactive effects of $\mathrm{CU}$ traits and traumatic stress on total observed child aggression exhibited during the SuperBuilder game. The overall model was not significant in the prediction of aggression, with $F(3,19)=0.27, p=.85, \mathrm{R}^{2}=0.05$.

\section{Addressing Aim IIa: Investigating the interactive effects of $\mathrm{CU}$ and anxiety on} aggression in the presence versus absence of distress cues

Table 3 also presents results from hierarchical regression analyses examining the main and interactive effects of CU traits and anxiety on child aggression exhibited during the SuperBuilder game, broken down by condition (i.e., presence versus absence of others' distress salience). 
Observed aggression in the absence of a distress cue. The overall model was significant, $F(3,40)=4.41, p=.01 ; \mathrm{R}^{2}=0.34$. Anxiety and $\mathrm{CU}$ traits each significantly predicted aggression in this condition —explaining $16.2 \%$ and $6.5 \%$, respectively, of the variance in aggression in the absence of a distress cue. As a main effect, $\mathrm{CU}$ positively predicted observed aggression, whereas anxiety as a main effect negatively predicted observed aggression. In addition, the product term examining the interactive effect between $\mathrm{CU}$ traits and anxiety contributed additional, unique predictive value $(F(1$, $40)=4.54, p=.04 ; \mathrm{R}^{2} \Delta=0.12$ ), indicating that the association between $\mathrm{CU}$ traits and aggression in the absence of a distress cue was not uniform across varying levels of anxiety.

Follow-up analyses examined simple slopes associated with high, medium, and low levels of anxiety. High was defined as one standard deviation above the centered mean anxiety total score, medium was defined as within one standard deviation of the centered mean anxiety total score, and low was defined as one standard deviation below the centered mean anxiety total score. Analyses revealed that CU traits were significantly predictive of increased aggression in the absence of a distress cue among children with medium and high levels of anxiety $(\beta=0.16, \mathrm{SE}=0.06,95 \% \mathrm{CI}=0.03-0.29$ and $\beta=0.37$, $\mathrm{SE}=0.14,95 \% \mathrm{CI}=0.10-0.65$, respectively). In contrast, $\mathrm{CU}$ traits were not predictive of increased aggression in the absence of a distress cue among children with low levels of anxiety $(\beta=-0.05, \mathrm{SE}=0.09,95 \% \mathrm{CI}=-0.24-0.14)$. Figure 5 presents a graphical depiction of the interactive relationship between $\mathrm{CU}$ and anxiety when predicting aggression in the absence of a distress cue. 
Observed aggression in the presence of a distress cue. The overall model was not significant in the prediction of aggression in the presence of a distress cue, $F(3$, $40)=0.31, p=.82 ; \mathrm{R}^{2}=0.04$. Similarly, neither $\mathrm{CU}$, anxiety, nor their interaction significantly predicted observed aggression in the presence of a distress cue.

Addressing Aim IIb: Investigating the interactive effects of $\mathrm{CU}$ and traumatic stress on aggression in the presence versus absence of distress cues

Table 4 also presents results from hierarchical regression analyses examining the main and interactive effects of $\mathrm{CU}$ traits and traumatic stress on child aggression exhibited during the SuperBuilder game, broken down by condition (i.e., presence versus absence of others' distress salience).

Aggression in the absence of a distress cue. The overall model was not significant in the prediction of aggression, with $F(3,19)=0.36, p=.79, \mathrm{R}^{2}=0.05$.

Aggression in the presence of a distress cue. The overall model was not significant in the prediction of aggression, with $F(3,19)=0.25, p=.86, \mathrm{R}^{2}=0.04$. Addressing Aim IIIa: Elucidating the main and interactive effects of CU and anxiety on perceptions of a potential victim's emotional state in an experimental context

Tables 5 and 6 present results from hierarchical regression analyses examining the main and interactive effects of $\mathrm{CU}$ traits and anxiety on child ratings of opponent emotions in neutral and distress cue conditions (respectively) in the SuperBuilder game.

Ratings of opponent emotions in the absence of a distress cue. The overall models were not significant in predicting child ratings of opponent "calm" $(F(3,38)=0.12$ $\left.p=.95 ; \mathrm{R}^{2}=0.01\right)$, "happy" $\left(F(3,39)=1.01, p=.40 ; \mathrm{R}^{2}=0.06\right)$, "angry" $(F(3,39)=1.49$, 
$\left.p=.23 ; \mathrm{R}^{2}=0.11\right)$, "sad" $\left(F(3,39)=0.77, p=.52 ; \mathrm{R}^{2}=0.04\right)$, and "scared" $(F(3,39)=0.20$, $\left.p=.90 ; \mathrm{R}^{2}=0.03\right)$ feelings.

Ratings of opponent emotions in the presence of a distress cue. The overall models were not significant in predicting child ratings of opponent "calm" $(F(3$, $\left.39)=1.89, p=.15 ; \mathrm{R}^{2}=0.11\right)$, “happy” $\left(F(3,39)=2.04, p=.12 ; \mathrm{R}^{2}=0.12\right)$, “angry” $(F(3$, $\left.39)=2.17, p=.11 ; \mathrm{R}^{2}=0.08\right)$, "sad" $\left(F(3,39)=0.07, p=.97 ; \mathrm{R}^{2}=0.01\right)$, and "scared" $(F(3$, 39) $\left.=1.69, p=.19 ; \mathrm{R}^{2}=0.09\right)$ feelings.

\section{Change in ratings of opponent emotions between neutral- and distress-cue}

conditions. Table 7 presents results from hierarchical regression analyses examining the main and interactive effects of CU traits and anxiety on change in child ratings of opponent emotions between neutral and distress cue conditions in the SuperBuilder game. Overall models were not significant in predicting change in ratings of opponent "calm" $\left(F(3,38)=1.59, p=.21 ; \mathrm{R}^{2}=0.09\right)$, "scared" $\left(F(3,39)=0.79, p=.51 ; \mathrm{R}^{2}=0.07\right)$, and "sad" $\left(F(3,39)=0.05, p=.98, \mathrm{R}^{2}=0.01\right)$ feelings. The overall model was significant in the prediction of change in ratings of opponent "angry" feelings, $F(3,39)=3.49, p=.02 ; \mathrm{R}^{2}$ $=0.15$. However, neither $\mathrm{CU}$ traits nor anxiety significantly predicted change in ratings of opponent "angry" feelings between the two conditions. Similarly, the product term examining the interactive effect between CU traits and anxiety did not significantly predict change in ratings of opponent "angry" feelings between the two conditions. The overall model was significant in the prediction of change in ratings of opponent "happy" feelings was significant, $F(3,39)=3.73, p=.02 ; \mathrm{R}^{2}=0.19$. Neither anxiety nor its interaction with CU traits significantly predicted change in ratings of opponent "happy" feelings between the two conditions. However, CU traits were a significant negative 
predictor in this model. Specifically, the greater the child's CU severity, the less change in ratings between the neutral- and distress-cue conditions.

\section{Addressing Aim IIIb: Investigating the main and interactive effects of $\mathrm{CU}$ and traumatic stress on perceptions of a potential victim's emotional state in an experimental context}

Tables 8-9 present results from hierarchical regression analyses examining the main and interactive effects of $\mathrm{CU}$ traits and traumatic stress on child ratings of opponent emotions in neutral and distress cue conditions in the SuperBuilder game.

Ratings of opponent emotions in the absence of a distress cue. The overall models were not significant in predicting child ratings of opponent "calm" $(F(3$, $\left.17)=0.39, p=.76 ; \mathrm{R}^{2}=0.07\right)$, "happy" $\left(F(3,18)=0.63, p=.61 ; \mathrm{R}^{2}=0.09\right)$, "angry" $(F(3$, 18)=1.04, $\left.p=.40 ; \mathrm{R}^{2}=0.20\right)$, "sad" $\left(F(3,18)=1.09, p=.38 ; \mathrm{R}^{2}=0.13\right)$, and "scared" $(F(3$, 18) $\left.=0.36, p=.78 ; \mathrm{R}^{2}=0.12\right)$ feelings.

Ratings of opponent emotions in the presence of a distress cue. The overall models were not significant in predicting child ratings of opponent "happy" $(F(3$, $\left.18)=1.07, p=.39 ; \mathrm{R}^{2}=0.12\right)$, “angry" $\left(F(3,18)=0.41, p=.75 ; \mathrm{R}^{2}=0.10\right)$, and "sad" $(F(3$, 18)=0.37, $p=.77 ; \mathrm{R}^{2}=0.07$ ) feelings. The overall model was significant in the prediction of ratings of opponent "scared" feelings, $F(3,18)=7.91, p=.001 ; \mathrm{R}^{2}=0.36$. Child CU was a significant negative predictor, and child traumatic stress was a significant positive predictor, of ratings of opponent "scared" feelings. Specifically, greater traumatic stress was associated with higher ratings, and greater $\mathrm{CU}$ was associated with lower ratings, of opponent "scared" feelings. The overall model was also significant in the prediction of ratings of opponent "calm" feelings, $F(3,18)=4.18, p=.02 ; \mathrm{R}^{2}=0.46$. Child CU was a 
significant positive predictor of ratings of opponent "calm" feelings. Specifically, greater CU was associated with higher ratings of opponent "calm" feelings.

\section{Change in ratings of opponent emotions between neutral- and distress-cue}

conditions. Table 10 presents results from hierarchical regression analyses examining the main and interactive effects of $\mathrm{CU}$ traits and traumatic stress on change in child ratings of opponent emotions between neutral and distress cue conditions in the SuperBuilder game. The overall models were not significant in predicting change in ratings of opponent “calm" $\left(F(3,17)=0.87, p=.48 ; \mathrm{R}^{2}=0.24\right)$, "happy" $\left(F(3,18)=1.95, p=.16 ; \mathrm{R}^{2}=0.27\right)$, “angry" $\left(F(3,18)=0.20, p=.90 ; \mathrm{R}^{2}=0.03\right)$, and "sad" $\left(F(3,18)=0.23, p=.88 ; \mathrm{R}^{2}=0.08\right)$ feelings. The overall model was significant in the prediction of change in ratings of opponent "scared" feelings, $F(3,18)=6.97, p=.003 ; \mathrm{R}^{2}=0.28$. However, neither CU traits nor traumatic stress significantly predicted change in ratings of opponent "scared" feelings between the two conditions. Similarly, the product term examining the interactive effect between CU traits and traumatic stress did not significantly predict change in ratings of opponent "scared" feelings between the two conditions.

\section{Addressing Aim IVa: Elucidating the main and interactive effects of CU and anxiety on parasympathetic response to others' distress}

Table 11 presents results from hierarchical regression analyses examining the main and interactive effects of CU traits and anxiety on baseline parasympathetic functioning (RSA $A_{\text {Resting }}$ ) and on parasympathetic response exhibited during the Distress Task (RSA $\left.A_{\text {Reactivity }}\right)$. Models were not significant in the prediction of RSA Resting, $F(3$, 39) $=0.98, p=.41, \mathrm{R}^{2}=0.09$, nor in the prediction of $\mathrm{RSA}_{\text {Reactivity }}, F(3,39)=0.75, p=.53, \mathrm{R}^{2}$ $=.03$. 
Table 12 presents results from HLM analyses examining the main and interactive effects of CU, anxiety, and their interaction associated with minute-to-minute changes in RSA Distress across time. RSA Resting, entered as a covariate, was a significant positive predictor of RSADistress across time, and the interaction between time and child anxiety was a significant negative predictor of RSA Distress. Time, $\mathrm{CU}$, anxiety, and the interactions between Time and CU, and Time and the product term of CU and anxiety, were not significant predictors of in RSADistress.

Follow-up analyses probing the significant AnxietyXTime interaction in the prediction of RSA Distress across time examined RSA Distress across time among the subgroups of youth with high versus low levels of anxiety. High anxiety was defined as above the mean MASC total score, and low anxiety was defined as below the mean MASC total score. Among youth with high anxiety, analyses indicated that RSAResting (the covariate) and Time were significant predictors of $\mathrm{RSA}_{\text {Distress }}(\mathrm{B}=0.99, \mathrm{SE}=0.05$, $t(120)=20.45, p<.001$ and $\mathrm{B}=-0.09, \mathrm{SE}=0.04, t(120)=-2.16, p=.03$, respectively).

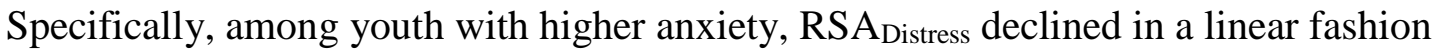
from minute 1 through minute 5 during exposure to others' distress. In contrast, among youth with low anxiety, while RSAResting (the covariate) was a significant predictor of $\mathrm{RSA}_{\text {Distress }}(\mathrm{B}=0.90, \mathrm{SE}=0.05, t(100)=18.83, p<.001)$, Time was not a significant predictor $(\mathrm{B}=-0.004, \mathrm{SE}=0.04, t(100)=-0.11, p=.91)$. That is, among youth with higher anxiety severity, RSA patterns suggest progressive parasympathetic suppression across time during exposure to others' distress, whereas exposure to others distress is not associated with progressive parasympathetic suppression across time in youth with lower anxiety severity. 
Figure 6 presents a graphical depiction of the relationships between anxiety and RSA $A_{\text {Distress }}$ across time.

\section{Addressing Aim IVb: Elucidating the interactive effects of $\mathrm{CU}$ and traumatic stress on parasympathetic-based response to others' distress}

Table 13 presents results from hierarchical regression analyses examining the main and interactive effects of $\mathrm{CU}$ traits and traumatic stress on baseline parasympathetic functioning $\left(\mathrm{RSA}_{\text {Resting }}\right)$ and on parasympathetic response exhibited during the Distress Task (RSAReactivity). Models were not significant in the prediction of RSA $A_{\text {Resting }} F(3$, 19) $=0.38, p=.77, \mathrm{R}^{2}=0.03$, nor in the prediction of $\mathrm{RSA}_{\text {Reactivity }}, F(3,19)=0.71, p=.56, \mathrm{R}^{2}$ $=.05$.

Table 14 presents results from HLM analyses examining the main and interactive effects of $\mathrm{CU}$, anxiety, and their interaction associated with minute-to-minute changes in RSA $_{\text {Distress }}$ across time. Time, $\mathrm{CU}$, traumatic stress, and their interactions were not significant predictors of RSADistress changes across time.

\section{DISCUSSION}

\section{Overview}

The present study examined complex relationships between youth CU traits, observed aggression, anxiety, trauma, perceptions of others' emotions, and physiological and behavioral responses to other's distress. Overall, these results derived from observational child aggression data are consistent with previous research that has only

utilized questionnaire-based data on child aggression (e.g., Fanti et al., 2013; Humayun et al., 2013; Rosan et al., 2015) in suggesting that CU traits are associated with greater aggression in the presence of higher levels of anxiety, and further clarify specific 
conditions under which this relationship applies. Specifically, the present findings obtained with an experimental paradigm indicate that anxiety moderates the effect of $\mathrm{CU}$ on child aggression, but only in the absence of salient distress cues from a potential victim. These findings extend research suggesting that children with $\mathrm{CU}$ traits and anxiety are more aggressive than children with elevated CU but not anxiety, as well as children low on both CU traits and anxiety (Fanti et al., 2013; Kahn et al., 2012). Collectively, findings have both theoretical implications for CU traits as a construct, and clinical relevance in the prevention and situational attenuation of aggression.

\section{Aggression}

The present work also adds to an increasing body of research documenting a strong relationship between CU traits and aggression (e.g., Fanti et al., 2009; Waschbusch et al., 2004), given that CU traits — and not just their interaction with anxiety-positively predicted observed aggression towards the opponent when the opponent's distress was not apparent. Results further supported the findings of van Baardewijk and colleagues (2009), who observed in a similar task that the relationship between CU traits and aggression changes when distress is made salient; however, the present study was the first to consider the role of anxiety in this relationship.

Theoretical distinctions between children with CU traits and anxiety versus children with CU traits but no anxiety are supported by the observed interaction. It appears that anxiety provides useful predictive information on the clinical presentation of CU traits, particularly in ambiguous social situations during which potential victims' distress is unclear. Interestingly, although anxiety by itself predicted reduced aggression under such ambiguous circumstances, anxiety actually sensitized youth with CU to 
aggress more than seen in CU youth without anxiety. It is possible that the increased attention to distress cues noted among CU youth experiencing anxiety represents a sensitivity to negative emotional cues in general, similar to the attentional biases towards negative- and threat-related cues (Mogg \& Bradley, 2005; Reid et al., 2006), and bias towards interpreting ambiguous information negatively (Taghavi et al., 2000) documented among anxious children. While CU traits have not previously been associated with a hostile attribution bias (HAB; Dodge, Price, Bachorowski, \& Newman, 1990; Frick et al., 2003a; Helseth, Waschbusch, King, \& Willoughby, 2015), perhaps the combination of cognitive biases associated with anxiety and the callousness of CU traits yields the impulsive, aggressive reactivity documented in these youth (e.g., Fanti et al., 2013; Kahn et al., 2013).

\section{Perceptions of Peer Emotions}

Indeed, it appears that CU traits are associated with difficulty understanding others' emotions, even when distress is made apparent. Youth CU traits were associated with lower ratings of opponent fear and higher ratings of calm in the presence of a distress cue from the opponent, as well as less change in participant ratings of perceived opponent happiness from the neutral to distress message during the SuperBuilder task. These findings support previous literature documenting that increased distress cue salience reduces_-but does not eliminate-emotion recognition deficits associated with $\mathrm{CU}$, as well as a tendency for CU youth to minimize victim distress resulting from aggression (Pardini \& Byrd, 2012). Importantly, in the present experimental study, distress was salient enough to reduce the impact of $\mathrm{CU}$ on observed aggressive behavior, regardless of perceived opponent emotion. The reduced impact of $\mathrm{CU}$ on aggression, 
regardless of perceived emotion of the opponent, suggests the potential for effecting change on a behavioral level relatively quickly, by increasing the "visibility" of a potential victim's distress — while supporting long-term reductions in aggressive behavior through training to not only recognize, but also anticipate, others' distress and respond with prosocial behavior.

\section{Physiological Responses}

With regard to physiological responses to others' distress, findings did not support the hypothesized interactive relationship between $\mathrm{CU}$ and anxiety in predicting resting RSA and RSA reactivity. The lack of effects was in contrast to the results of previous studies showing that $\mathrm{CU}$ traits are associated with blunted parasympathetic activity at rest (e.g., de Wied et al., 2012) and in response to threat and distress cues (e.g., AnastassiouHadjicharalambous \& Warden, 2008b). Given the relatively small sample size of the present study, and the relatively small nature of psychohysiological effects in studies comparing CNS activity of youth with and without CU traits (e.g., AnastassiouHadjicharalambous \& Warden, 2008b; de Wied et al., 2012; Musser et al. 2013), power to detect moderation effects may have been compromised. Interestingly, anxious youth showed greater parasympathetic suppression across time with extended exposure to another child's distress; the same was not true of non-anxious children. Existing literature indicates that high RSA reactivity in response to distressing stimuli may be a biomarker of reduced emotion regulation capabilities (Beauchaine, 2015). While sample size may have precluded detection of effects related to $\mathrm{CU}$ and its interaction with anxiety across time (as suggested by the trending effects noted in Table 9), findings related to anxiety and RSA reactivity over time hint that the specific parasympathetic response pattern 
associated with anxiety may explain anxiety-related heterogeneity in aggressive behavior among $\mathrm{CU}$ youth. As research both specific to $\mathrm{CU}$ traits and on empathy in general suggests that blunted parasympathetic and sympathetic activity may be partially responsible for deficits in empathy-related responding, rather than solely the failure to detect and understand emotional cues (e.g., Blair et al., 2006; Shirtcliff et al., 2009), further investigation is needed to identify whether physiological responses contribute to anxiety-related heterogeneity among $\mathrm{CU}$ youth—particularly given the increased attention to distress cues observed in CU youth experiencing anxiety symptoms (Kimonis et al., 2012). Future studies would do well to investigate specific profiles of parasympathetic response to others' distress across time in larger samples.

\section{Trauma-related Findings}

Statistical power may also have interfered with detection of trauma-related moderation effects, as traumatic stress data were available only for the part of the sample that experienced a traumatic event $(\mathrm{N}=25)$. However, among these youth, traumatic stress symptom severity still predicted increased ratings of opponent fear in the presence of a distress cue, in line with literature documenting enhanced identification of fear-related cues among trauma-exposed youth (e.g., Masten et al., 2008). Child CU traits were also positively correlated with traumatic stress—-but not anxiety—indicating a potential relationship between $\mathrm{CU}$ and traumatic stress that is not accounted for by trauma-related anxiety. The high rate of trauma exposure in this CP-enhanced community sample sheds light on the overall need to understand potential trauma responses—particularly given evidence that traumatic stress influences perceptions of others' fear-and the observed 
correlation between $\mathrm{CU}$ traits and traumatic stress suggests the need for further exploration of how these constructs co-occur in trauma-exposed youth.

\section{Clinical Implications}

Important clinical and practical implications follow from study findings as a

whole. Children with CU traits may benefit from training to anticipate situations that may cause others' distress, to attend to, and accurately identify, distress cues (and cues to the potential for distress) and to alter behavior accordingly with contingency management and prosocial behavior training. Given that high anxiety levels increase the likelihood for aggression in the absence of salient distress cues (and the presence of neutral, ambiguous cues), identifying children with high levels of CU traits and anxiety for emotional training-based intervention may be particularly important. In potentially aggressive situations involving children with CU traits, increasing the salience of others' distress cues (and/or potential for distress) may attenuate aggressive outcomes. Interestingly, the widely encouraged practice of ignoring, or remaining confident/neutral when facing aggression and provocation may not apply to victims of aggressors with $\mathrm{CU}$ - and especially aggressors with CU and anxiety. In these situations, it may be best for victims to make their distress salient to the aggressor in order to reduce aggression.

\section{Limitations}

Conclusions should be interpreted in light of several study limitations. The first set of limitations relates to the nature of the study sample. The sample size may have yielded inadequate statistical power to detect small-to-medium effects, particularly lowmagnitude psychophysiological effects, and trauma-related effects that were, by necessity, examined in an even smaller participant subset. Sample size precluded 
investigation of the relationships of interest while controlling for demographic factors relevant to aggression, such as age and gender (Baillargeon et al., 2007; Costello, Mustillo, Erklani, \& Angold, 2003; Loeber \& Hay, 1997). Future research would do well to investigate physiological responses - including indices of both parasympathetic and sympathetic activity, given research indicating blunted parasympathetic and sympathetic responses in CU youth (e.g., Blair et al., 1999; de Wied et al., 2012)— to others' distress in larger samples, as well as the potential role of trauma in differences between CU youth with and without anxiety in a trauma-exposed sample. In addition, the CP-enhanced sample yielded data that did not conform to normality standards for typical linear regression analyses. While bootstrapping techniques allowed for correction and increased confidence in results, future research should investigate relationships in larger clinical samples, so that statistical techniques geared towards analyzing skewed data (e.g., Poisson regression) may be used. Relatedly, as CU traits are typically conceptualized in the context of child behavior problems, conducting further study in a clinical sample would allow more in-depth analysis of the CU construct. However, the practice of blending community recruitment with recruitment of youth with serious behavior problems in order to yield a $\mathrm{CP}$-enhanced sample is not unprecedented in the $\mathrm{CU}$ and anxiety literature (e.g., Docherty et al., 2015). Third, the sample included mostly Hispanic youth, with few African American children and few non-Hispanic Caucasian children. Although this sample is fairly representative of the ethnic demographics of the city in which data were collected (70\% Hispanic, 11.9\% White non-Hispanic, 16.3\% Black or African American non-Hispanic; U.S. Census Bureau, 2010), results may not generalize to other populations and cultures. 
A second set of limitations relates to the nature of data collected, including measures in the SuperBuilder task and information on traumatic exposure. Although data were collected on child perception of peer emotions, data were not collected on child perception of peer intentions, precluding the assessment of interpretive biases and social goals during the SuperBuilder task. Given the reactive profile of children with CU and anxiety (e.g., Fanti et al., 2013), and the potential for interactive social-cognitive biases associated with both CU (e.g., Pardini, 2011) and anxiety (e.g., Taghavi et al., 2000), future research would do well to assess the role of cognition more extensively. Moreover, children displayed relatively high aggression overall during the SuperBuilder task, reducing the variability of aggression that could be predicted. Perhaps the aggression task evoked competitive behavior that interfered with the emotional matching theorized to underlie empathy (Eisenberg \& Eggum, 2009), as observed in adult research (e.g., Cikara, Bruneau, \& Saxe, 2011; Weyers, Mühleberger, Kund, Hess, \& Pauli, 2009). With regard to traumatic exposure, information on exposure to specific trauma types experienced (e.g., physical abuse, witnessing community violence, natural disaster exposure) was not collected. As a result, it was not possible to examine how traumarelated findings may vary across various forms of traumatic exposure. Given previous investigations indicating more extensive trauma histories among CU youth with anxiety in comparison to their non-anxious counterparts (e.g., Humayun et al., 2015; Kimonis et al., 2012), and research suggesting that emotional numbing symptoms link violence exposure and delinquency (Allwood et al., 2011), it is possible that specific forms of traumatic exposure (e.g., violence exposure) are more strongly associated with aggression and aspects of emotional processing among youth with $\mathrm{CU}$ traits than other forms of 
traumatic exposure (e.g., exposure to a natural disaster). Future studies would do well to collect information on youths' exposure to specific forms of trauma.

A final limitation relates to study time period. Given the short-term nature of the laboratory-based task, long-term conclusions cannot be drawn. Similarly, long-term predictions of behavior and outcomes cannot be made, given the absence of longitudinal follow-up data. While practice effects may preclude the administration of the SuperBuilder task as-is at regular intervals, perhaps further task development and sophistication (e.g., randomization of task conditions) would allow for more long-term comparison. Longitudinal reports and records-based (e.g., school disciplinary records) data would allow future researchers to examine the long-term predictive value of observed responses to others' distress among children with CU and anxiety.

\section{Future Directions}

In addition to the specific considerations for future research noted above, further investigation is needed in general to identify potential mechanisms by which $\mathrm{CU}$ and anxiety symptoms interact to increase aggression in the absence of distress cues. While study findings suggest that emotional processing plays a role in this relationship, research may do well to assess whether increases and decreases in aggression under these conditions are mediated by physiological responses, social cognitive processes (such as a $\mathrm{HAB}$ or perceptions of dominance), or both.

\section{Summary and Conclusions}

Despite the limitations noted above, the present study was the first to examine relationships between $\mathrm{CU}$ traits, anxiety, and observed aggression in an experimental task allowing manipulation of distress cue salience, and the first to examine relationships 
between CU traits, anxiety, and parasympathetic responses to others' distress. Findings extend existing research by highlighting the role of emotional cues in the observed aggressive responses of children with $\mathrm{CU}$ traits, particularly $\mathrm{CU}$ youth experiencing anxiety symptoms. Although previous research has equated CU traits with a lack of anxiety (see Frick \& White, 2008), the present study joins a growing body of work indicating that these two constructs are not mutually exclusive, but rather may interact to predict some of the most concerning outcomes. The distinction between subset of children with CU traits with and without anxiety appears to have significant clinical and theoretical utility in predicting the heterogeneity of behavior among youth with $\mathrm{CU}$ traits, as well as pointing to potential treatment targets; future research must further investigate the nature of emotional processing deficits, and their role in the development of $\mathrm{AB}$, among children with CU traits and anxiety. 


\section{REFERENCES}

Allwood, M.A., Bell, D.J., \& Horan, J. (2011). Posttrauma numbing of fear, detachment, and arousal predict delinquent behaviors in early adolescence. Journal of Clinical Child \& Adolescent Psychology, 40(5), 659-667. doi:10.1080/15374416.2011.597081.

American Psychiatric Association. (2013). Diagnostic and statistical manual of mental disorders (5th ed.). Arlington, VA: American Psychiatric Publishing.

Anastassiou-Hadjicharalambous, X., \& Warden, D. (2008a). Cognitive and affective perspective-taking in conduct-disordered children high and low on callousunemotional traits. Child and Adolescent Psychiatry and Mental Health, 2(16), 111. doi:10.1186/1753-2000-2-16.

Anastassiou-Hadjicharalambous, X., \& Warden, D. (2008b). Physiologically-indexed and self-perceived affective empathy in conduct-disordered children high and low on callous unemotional traits. Child Psychiatry and Human Development, 39, 503517.

Appelhans, B. M., \& Luecken, L. J. (2006). Heart rate variability as an index of regulated emotional responding. Review of General Psychology, 10(3), 229-240.

Baillargeon, R. H., Zoccolillo, M., Keenan, K., Côté, S., Pérusse, D., Wu, H., Boivin, M., \& Tremblay, R. E. (2007). Gender differences in physical aggression: A prospective population-based survey of children before and after 2 years of age. Developmental Psychology, 43(1), 13-26. doi: 10.1037/0012-1649.43.1.13

Baron, R.M., \& Kenny, D.A. (1986). The moderator-mediator variable distinction in social psychological research: Conceptual, strategic, and statistical consideration. Journal of Personality and Social Psychology, 51, 1173-1182. doi:10.1037/00223514.51.6.1173.

Beauchaine, T. P. (2015). Respiratory sinus arrhythmia: A transdiagnostic biomarker of emotion dysregulation and psychopathology. Current Opinions in Psychology, $1(3), 43-47$.

Blair, R. J. R. (1999). Responsiveness to distress cues in the child with psychopathic tendencies. Personality and Individual Differences, 27(1), 135-145. doi: 10.1016/S0191-8860(98)00231-1

Blair, R. J. R., Budhani, S., Colledge, E., \& Scott, S. (2005). Deafness to fear in boys with psychopathic tendencies. Journal of Child Psychology and Psychiatry, 46(3), 327-336. 
Blair, R. J., Colledge, E., Murray, L., \& Mitchell, D. G. (2001). A selective impairment in the processing of sad and fearful expressions in children with psychopathic tendencies. Journal of Abnormal Child Psychology, 29(6), 491-498.

Blair, R. J. R., Peschardt, K. S., Budhani, S., Mitchell, D. G. V., \& Pine, D. S. (2006). The development of psychopathy. Journal of Child Psychology and Psychiatry, $47(3), 262-275$.

Bollen, K. A., \& Stine, R. (1990). Direct and indirect effects: Classical and bootstrap estimates of variability. Sociological Methodology, 20, 115-140.

Canivez, G. L., Konold, T. R., Collins, J. M., \& Wilson, G. (2009). Construct validity of the Wechsler Abbreviated Scale of Intelligence and Wide Range Intelligence Test: Convergent and structural validity. School Psychology Quarterly, 24(4), 252-265. doi: 10.1037/a0018030

Christian, R.E., Frick, P.J., Hill, N.L., Tyler, L., \& Frazer, D.R. (1997). Psychopathy and conduct problems in children: II. Implications for subtyping children with conduct problems. Journal of the American Academy of Child \& Adolescent Psychiatry, $36,233-241$.

Cikara, M., Bruneau, E. G., \& Saxe, R. R. (2011). Us and them: Intergroup failures of empathy. Current Directions in Psychological Science, 20(3), 149-153. doi: $10.1177 / 0963721411408713$

Costello, E. J., Mustillo, S., Erkanli, A., Keeler, G., \& Angold, A. (2003). Prevalence and development of psychiatric disorders in childhood and adolescence. Archives of General Psychiatry, 60, 837-844. doi:10.1001/archpsyc.60.8.837.

Dadds, M. R.., Cauchi, A. J., Wimalaweera, S., Hawes, D. J., \& Brennan, J. (2012). Outcomes, moderators, and mediators of empathic-emotion recognition training for complex conduct problems in childhood. Psychiatry Research, 199, 201-207

Dadds, M. R., El Masry, Y., Wimalaweera, S., \& Guastella, A. J. (2008). Reduced eye gaze explains "fear blindness" in childhood psychopathic traits. Journal of the American Academy of Child and Adolescent Psychiatry, 47(4), 455-463. doi: 10.1097/CHI.0b013e31816407f1

Dadds, M. R., Hawes, D. J., Frost, A. D. J., Vassallo, S., Bunn, P., Hunter, K., \& Merz, S. (2009). Learning to "talk the talk": The relationship of psychopathic traits to deficits in empathy across childhood. Journal of Child Psychology and Psychiatry, 50(5), 599-606. 
Dadds, M. R., Jambrak, J., Pasalich, D., Hawes, D. J., \& Brennan, J. (2011). Impaired attention to the eyes of attachment figures and the developmental origins of psychopathy. Journal of Child Psychology and Psychiatry, 52(3), 238-245

Dadds, M. R., Perry, Y., Hawes, D. J., Merz, S., Riddell, A. C., Haines, D. J., Solak, E., $\&$ Abeygunawardane, A. I. (2006). Attention to the eyes and fear-recognition deficits. British Journal of Psychopathy, 189, 280-281.

Dalgleish, T., Moradi, A. R., Taghavi, M. R., Neshat-Doost, H. T., \& Yule, W. (2001). An experimental investigation of hypervigilance for threat in children and adolescents with post-traumatic stress disorder. Psychological Medicine, 31, 541-547.

de Wied, M. van Boxtel, A., Matthys, W., \& Meeus, W. (2012). Verbal, facial, and autonomic responses to empathy-eliciting film clips by disruptive male adolescents with high versus low callous unemotional traits. Journal of Abnormal Child Psychology, 40(2), 211-223. doi: 10.1007/s10802-011-9557-8.

Docherty, M., Boxer, P., Huesmann, L. R., O’Brien, M., \& Bushman, B. J. (2015). Exploring primary and secondary variants of psychopathy in adolescents in detention and in the community. Journal of Clinical Child and Adolescent Psychology, 1-15. doi: 10.1080/15374416.2014.979934

Dodge, K. A., \& Coie, J. D. (1987). Social-Information-Processing factors in reactive and proactive aggression in children's peer groups. Journal of Personality and Social Psychology, 53(6), 146-1158.

Dodge, K. A., Price, J. M.., Bachorowski, J., \& Newman, J. P. (1990). Hostile attributional biases in severely aggressive adolescents. Journal of Abnormal Psychology, 99(4), 385-392. doi: 10.1037/0021-843X.99.4.385

Efron, B. (1979). Computers and the theory of statistics: Thinking the unthinkable. Society for Industrial and Applied Mathematics Review, 21, 460-480.

Efron, B., \& Tibshirani, R. J. (1993). An introduction to the bootstrap. New York, NY: Chapman \& Hall.

Eisenberg, N., \& Eggum, N. D. (2009). Empathic responding: Sympathy and personal distress. In: J. Decety \& W. Ickes (Eds), The social neuroscience of empathy (pp. 71-83). Cambridge, MA: MIT Press.

Eisenberg, N., Eggum, N. D., \& Di Giunta, L. (2010). Empathy-related responding: Associations with prosocial behavior, aggression, and intergroup relations. Social Issues and Policy, 4(1), 143-18. doi:10.1111/j.1751-2409.2010.01020.x. 
Eisenberg, N., \& Fabes, R. A. (1990). Empathy: Conceptualization, measurement, and relation to prosocial behavior. Motivation and Emotion, 14(2), 131-149.

Essau, C.A., Sasagawa, S., \& Frick, P.J. (2006). Callous-unemotional traits in a community sample of adolescents. Assessment, 13, 454-469.

Euler, F., Jenkel, N., Stadler, C., Schmeck, K., Fegert, J. M., Kolch, M., \& Schmit, M. (2015). Variants of girls and boys with Conduct Disorder: Anxiety symptoms and callous-unemotional traits. Journal of Abnormal Child Psychology, 43(3), 773785.

Fanti, K. A., Demetriou, C. A., \& Kimonis, E. R. (2013). Variants of callous unemotional conduct problems in a community sample of adolescents. Journal of Youth and Adolescence, 42, 964-979.

Fanti, K.A. Frick, P.J., \& Georgiou, S. (2009). Linking callous-unemotional traits to instrumental and non-instrumental forms of aggression. Journal of Psychopathology and Behavioral Assessment, 31, 285-298.

Foa, E. B., Johnson, K. M., Feeny, N. C., \& Treadwell, K. R. (2001). The child PTSD Symptom Scale: a preliminary examination of its psychometric properties. Journal of Clinical Child Psychology, 30(3), 376-384.

Fontaine, N. M., McCrory, E. J. Boivin, M., Moffitt, T. E. \& Viding, E. (2011). Predictors and outcomes of joint trajectories of callous unemotional traits and conduct problems in childhood. Journal of Abnormal Psychology, 120(3), 730742 .

Frick P. J., Cornell, A. H., Bodin, S. D., Dane, H. A., Barry, C. T., \& Loney, B. R. (2003a). Callous-unemotional traits and developmental pathways to severe aggressive and antisocial behavior. Developmental Psychology, 39, 246-260.

Frick, P. J., \& Dantagnan, A. L. (2005). Predicting the stability of conduct problems in children with and without callous-unemotional traits. Journal of Child and Family Studies, 14(4), 469-485.

Frick, P. J., \& Ellis, M. (1999). Callous-unemotional traits and subtypes of conduct disorder. Clinical Child and Family Psychology Review, 2, 149-168.

Frick, .P. J, Kimonis, E. R., Dandreaux, D. M, \& Farell, J. M. (2003b). The 4 year stability of psychopathic traits in non-referred youth. Behavioral Science \& Law, $21,713-736$. 
Frick, P. J., Ray, J. V., Thornton, L. C., \& Kahn, R. E. (2014). Can callous-unemotional traits enhance the understanding, diagnosis, and treatment of serious conduct problems in children and adolescents? A comprehensive review. Psychological Bulletin, 140(1), 1-57. doi: 10.1037/a0033076

Frick, P. J., \& White, S. F. (2008). Research review: The importance of callousunemotional traits for developmental models of aggressive and antisocial behavior. Journal of Child Psychology and Psychiatry, 49(4), 359-375. doi: 10.1111/j.1469-7610.2007.01862.x

Giancola, P.R., \& Zeichner, A. (1995). Construct validity of a competitive reaction-time aggression paradigm. Aggressive Behavior, 21, 199-204.

Gillihan, S. J., Aderka, I. M., Conklin, P. H., Capaldi, S., \& Foa, E. B. (2013). The Child PTSD Symptom Scale: Psychometric properties in female adolescent sexual assault survivors. Psychological Assessment, 25(1), 23-31. doi: 10.1037/a0029553

Greenhill, L. L., Swanson, J. M., Vitiello, B., ... Wigal, T. (2001). Impairment and deportment responses to different methylphenidate doses in children with ADHD: The MTA titration trial. Child and Adolescent Psychiatry, 40, 168-179.

Hawes, S. W., Byrd, A. L., Henderson, C. E. Gazda, R. L., Burke, J. D., Loeber, R., \& Pardini, D. A. (2014a). Refining the parent-reported Inventory of CallousUnemotional Traits in boys with conduct problems. Psychological Assessment, 26(1), 256-266. doi: 10.1037/a0034718

Hawes, D. J., Price, M. J., \& Dadds, M. R. (2014b). Callous-unemotional traits and the treatment of conduct problems in childhood and adolescence: A comprehensive review. Clinical Child \& Family Psychology Review, 17(3), 248-267. doi: 10.1007/s10567-014-0167-1

Hawkins, S. S., \& Radcliffe, J. (2006). Current measures of PTSD for children and adolescents. Journal of Pediatric Psychology, 31(4), 420-430.

Hayano, J., Sakakibara, Y., Yamada, A., Yamada, M., Mukai, S., Fujinami, T., ... Takata, K. (1991). Accuracy of assessment of cardiac vagal tone by heart rate variability in normal subjects. The American Journal of Cardiology, 67(2), 199204.

Hayes, A. F. (2012). PROCESS: A versatile computational tool for observed variable mediation, moderation, and conditional process modeling [White paper]. Retrieved from http://www.afhayes.com/public/process2012.pdf 
Helseth, S. A., Waschbusch, D. A., King, S., \& Willoughby, M. T. (2015). Aggression in children with conduct problems and callous-unemotional traits: Social information processing and response to peer provocation. Journal of Abnormal Child Psychology, 43(8), 1503-1514. doi: 10.1007/s10802-015-0027-6

Herpers, P. C., Klip, H., Rommelse, N. N., Greven, C. U., \& Buitelaar, J. K. (2016). Associations between high callous-unemotional traits and quality of life across youths with non-conduct disorder diagnoses. European Journal of Child and Adolescent Psychiatry, 25(5), 547-555. doi: 10.1007/s00787-015-0766-5

Herpers, P. C., Rommelse, N. N., Bons, D. M., Buitelaar, J. K., \& Scheepers, F. E. (2012). Callous-unemotional traits as a cross-disorders construct. Social Psychiatry and Psychiatric Epidemiology, 47(12), 2045-2064. doi: 10.1007/s00127-012-0513-X

Hoffman, M. L. (1984). Interaction of affect and cognition in empathy. In C. E. Izard, J. Kagan, \& R. B. Zajonc (Eds.), Emotions, cognition, and behavior (pp. 103-131). New York, NY: Cambridge University Press.

Holmbeck, G.N. (1997). Toward terminological, conceptual, and statistical clarity in the study of mediators and moderators: Examples from the child-clinical and pediatric psychology literatures. Journal of Consulting and Clinical Psychology, 65, 599610. doi:10.1037/0022-006X.65.4.599.

Humayun, S., Kahn, R. E., Frick, P. J., \& Viding, E. (2013). Callous unemotional traits and anxiety in a community sample of 7-year-olds. Journal of Clinical Child \& Adolescent Psychology, 43(1), 36-42. doi: 10.1080/15374416.2013.814539.

Jones, A. P., Laurens, K. R., Herba, C. M., Barker, G. J., \& Viding, E. (2009). Amygdala hypoactivity to fearful faces in boys with conduct problems and callousunemotional traits. American Journal of Psychiatry, 166(1), 95-102. doi: 10.1176/appi.ajp.2008.07071050

Karpman, B. (1948). Conscience in the psychopath: Another version. American Journal of Orthopsychiatry, 18, 455-491.

Kendall, P.C., \& Comer, J.S. (2011). Research methods in clinical psychology. In D.H. Barlow (ed.), The Oxford Handbook of Clinical Psychology (pp. 52-75). NY: Oxford University Press. doi:10.1093/oxfordhb/9780195366884.013.0004.

Kahn, R. E., Frick, P. J., Youngstrom, E. A., Youngstrom, J. K., Feeny, N. C., \& Findling, R. L. (2013). Distinguishing primary and secondary variants of callous unemotional traits among adolescents in a clinic-referred sample. Psychological Assessment, 25(3), 966-978. DOI: 10.1037/a0032880. 
Kimonis, E. R., Fanti, K. A., \& Singh, J. F. (2014). Establishing cut-off scores for the parent-reported Inventory of Callous-Unemotional Traits. Archives of Forensic Psychology, 1(1), 27-48.

Kimonis, E. R., Frick, P. J., Cauffman, E., Goldweber, A., \& Skeem, J. (2012). Primary and secondary variants of juvenile psychopathy differ in emotional processing. Development and Psychopathology, 24, 1091-1103.

Kimonis, E. R., Skeem, J. L., Cauffman, E., Dmitrieva, J. (2011). Are secondary variants of juvenile psychopathy more reactively violent and less psychosocially mature than primary variants? Law and Human Behavior, 35(5), 381-391.

Lee, Z., Salekin, R. T., \& Iselin, A. R. (2010). Psychopathic traits in youth: Is there evidence for primary and secondary subtypes? Journal of Abnormal Child Psychology, 38, 381-393. Doi: 10.1007/s10802-009-9372-7

Little, R. J. A., \& Rubin, D. B. (1987). Statistical analysis with missing data. New York, NY: John Wiley \& Sons.

Loeber, R., \& Hay, D. (1997). Key issues in the development of aggression and violence from childhood to early adulthood. Annual Review of Psychology, 48, 371-410. doi: 10.1146/annurev.psych.48.1.371

Lozier, L. M., Cardinale, E. M., VanMeter, J. W., \& Marsh, A. A. (2014). Mediation of the relationship between callous unemotional traits and proactive aggression by amygdala response to fear among children with conduct problems. Journal of the American Medical Association of Psychiatry, 71(6), 627-636. doi:10.1001/jamapsychiatry.2013.4540

Lynam, D. R., Caspi, A., Moffitt, T. E., Loeber, R., \& Stouthamer-Loeber, M. (2007). Longitudinal evidence that psychopathy scores in early adolescence predict adult psychopathy. Journal of Abnormal Psychology, 116, 155-165.

March J. S. (2013). Multidimensional Anxiety Scale for Children-2nd edition: Technical manual. Toronto, Ontario, Canada: Multi-Health Systems.

March, J. S., Parker, J. D., Sullivan, K., Stallings, P., Conners, C. K. (1997). The Multidimensional Anxiety Scale for Children (MASC): Factor structure, reliability, and validity. Journal of the American Academy of Child and Adolescent Psychiatry, 36(4), 554-565.

Marsh, A. A., Finger, E. C., Fowler, K. A., Adalio, C. J., Jurkowitz, I. T. N., Schechter, J. C., ... Blair, R. J. R. (2013). Empathic responsiveness in amygdala and anterior cingulate cortex in youths with psychopathic traits. Journal of Child Psychology and Psychiatry, 54(8), 900-910. doi:10.1111/jcpp.12063. 
McDonald, R., Dodson, M. C., Rosenfield, D., \& Jouriles, E. N. (2011). Effects of a parenting intervention on features in psychopathy in children. Journal of Abnormal Child Psychology, 39, 1013-1023. DOI: 10.1007/s10802-011-9512-8.

Mills-Koonce, W. R., Wagner, N. J., Willoughby, M. T., Stifter, C., Blair, C., \& Granger, D. A.. (2015). Greater fear reactivity and psychophysiological hyperactivity among infants with later conduct problems and callous-unemotional traits. Journal of Child Psychology and Psychiatry, 56(2), 147-154. doi: 10.1111/jcpp.12289

Moran, P., Rowe, .R, Flach, C., Briskman, J., Ford, T., Maughan, B., \& Goodman, R. (2009). Predictive value of callous-unemotional traits in a large community sample. Journal of the American Academy of Child and Adolescent Psychiatry, 48, 1079-1084. doi:10.1097/CHI.0b013e3181b766ab

Muñoz, L.C. (2009). Callous-unemotional traits are related to combined deficits in recognizing afraid faces and body poses. Journal of the American Academy of Child and Adolescent Psychiatry, 48(5), 554-562.

Muñoz, L.C., Frick, P. J., Kimonis, E. R., Aucoin, K. J. (2008). Types of aggression, responsiveness to provocation, and callous-unemotional traits in detained adolescents. Journal of Abnormal Child Psychology, 36, 15-28.

Muris, P., Merckelbach, H., Ollendick, T., King, N., \& Bogie, N. (2002). Three traditional and three new childhood anxiety questionnaires: Their reliability and validity in a normal adolescent sample. Behaviour Research and Therapy, 40, 753-772. doi: 10.1016/S0005-7967(01)00056-0

Musser, E. D., Galloway-Long, H. S., Frick, P. J., \& Nigg, J. T. (2013). Emotion regulation and heterogeneity in Attention-Deficit/Hyperactivity Disorder. Journal of the American Academy of Child and Adolescent Psychiatry, 52(2), 163-171. doi: 10.1016/j.jaac.2012.11.009

Nixon, R. D. V., Yule, W., Perrin, S., Meiser-Stedman, R., Dalgleish, T., Clark, D. M., \& Smith, P. (2013). The Child PTSD Symptom Scale: An update and replication of its psychometric properties. Psychological Assessment, 25(3), 1025-1031. doi: $10.1037 / \mathrm{a} 0033324$

Obradovic, J., Pardini, D. A., Long J. D., \& Loeber, R. (2007). Measuring interpersonal callousness in boys from childhood to adolescence: An examination of longitudinal invariance and temporal stability. Journal of Clinical Child and Adolescent Psychology, 36, 276-292. 
Pardini, D.A. (2006). The callousness pathway to severe violent delinquency. Aggressive Behavior, 32, 1-9.

Pardini, D. A., \& Byrd, A. L. (2012). Perceptions of aggressive conflicts and others' distress in children with callous-unemotional traits: 'I'll show you who's boss, even if you suffer and I get in trouble.' Journal of Child Psychology and Psychiatry, 53(3), 283-291. doi:10.1111/j.1469-7610.2011.02487.x

Pardini, D.A. (2011). Perceptions of social conflicts among incarcerated adolescents with callous-unemotional traits: 'You're going to pay. It's going to hurt, but I don't care'. Journal of Child Psychology and Psychiatry, 52, 248-255. doi: 10.1111/j.1469-7610.2010.02336.x

Porter, S. (1996). Without conscience or without active conscience? The etiology of Psychopathy revisited. Aggression and Violent Behavior, 1, 179-189.

Rasmussen, J. L. (1987). Estimating correlation coefficients: Bootstrap and parametric approaches. Psychological Bulletin, 101, 136-139.

Reid, S. C.., Salmon, K., \& Lovibond, P. F. (2006). Cognitive biases in childhood anxiety, depression, and aggression: Are they pervasive or specific? Cognitive Therapy and Research, 30, 531-549. doi: 10.1007/s10608-006-9077-y

Rosan, A., Frick, P. J., Gottlieb, K. A., \& Fasicaru, L. (2015). Callous-unemotional traits and anxiety in a sample of detained adolescents in Romania. Journal of EvidenceBased Psychotherapies, 15(1), 79-95.

Rowe, R., Maughan, B., Moran, P., Ford, T., Briskman, J., \& Goodman, R. (2010). The role of callous unemotional traits in the diagnosis of conduct disorder. Journal of Child Psychology and Psychiatry, 51(6), 688-695.

Russell, C. J., \& Dean, M. A. (2000). To log or not to log: Bootstrap as an alternative to the parametric estimation of moderation effects in the presence of skewed dependent variables. Organizational Research Methods, 3(2), 166-185.

Saklofske, D. H., Caravan, G., \& Schwartz, C. (2000). Concurrent validity of the Wechsler Abbreviated Scale of Intelligence (WASI) with a sample of Canadian children. Canadian Journal of School Psychology, 16(1), 87-94. doi: $10.1177 / 082957350001600106$

Shirtcliff, E. A., Vitacco, M. J., Graf, A. R., Gostisha, A. J., Merz, J. L., \& Zahn-Waxler, C. (2009). Neurobiology of empathy and callousness: Implications for the development of antisocial behavior. Behavioral Science and the Law, 27(2), 137171. doi: $10.1002 / \mathrm{bsl} .852$ 
Skeem, J. L., Poythress, N., Edens, J. F., Lilienfeld, S. O., \& Cale, E. M. (2003). Psychopathic personality or personalities? Exploring potential variants of psychopathy and their implications for risk assessment. Aggression and Violent Behavior, 8, 513-546.

Taghavi, M. R., Moradi, A. R., Neshat-Doost, H. T., Yule, W., \& Dalgleish, T. (2000). Interpretation of ambiguous emotional information in clinically anxious children and adolescents. Cognition and Emotion, 14(6), 809-822. doi: $10.1080 / 02699930050156645$

Tatar II, J. R., Cauffman, E., Kimonis, E. R., \& Skeem, J. L. (2012). Victimization history and posttraumatic stress: An analysis of psychopathy variants in male juvenile offenders. Journal of Child \& Adolescent Trauma, 5, 102-113. doi: 10.1080/19361521.2012.671794

Teicher, M. H., Andersen, S. L., Polcari, A., Anderson, C. M., \& Navalta, C. P. (2002). Developmental neurobiology of childhood stress and trauma. Psychiatric Clinics of North America, 25(2), 397-426. doi: 10.1016/S0193-953X(01)00003-X

Thomaes, S., Bushman, B. J., Stegge, H., \& Olthof, T. (2008). Trumping shame by blasts of noise: Narcissism, self-esteem, shame, and aggression in young adolescents. Child Development, 79(6), 1792-1801.

U.S. Census Bureau. (2010). Data Tables for Florida, Counties, and Incorporated Cities. Retrieved from: http://edr.state.fl.us/Content/population-demographics/2010census/data/index.cfm

Van Baardewijk, Y., Stegge, H., Bushman, B. J., \& Vermeiren, R. (2009). Psychopathic traits, victim distress and aggression in children. Journal of Child Psychology and Psychiatry, 50(6), 718-725. doi:10.1111/j.1469-7610.2008.02023.x.

Vaughn, M. G., Edens, J. F., Howard, M. O., \& Smith, S. T. (2009). An investigation of primary and secondary psychopathy in a statewide sample of incarcerated youth. Youth Violence and Juvenile Justice, 7(3), 172-188. doi: $10.1177 / 15412040009333792$

Waschbusch, D. A., Carrey, N. J., Willoughby, M. T., King, S., \& Andrade, B. F. (2007). Effects of Methylphenidate and behavior modification on the social and academic behavior of children with Disruptive Behavior Disorders: The moderating role of callous/unemotional traits. Journal of Clinical Child \& Adolescent Psychology, 36(4), 629-644. 
Waschbusch, D. A., Porter, S., Carrey, N., Kazmi, S. O., Roach, K. A., D’Amico, D. A. (2004). Investigation of the heterogeneity of disruptive behavior in elementaryage children. Canadian Journal of Behavioral Science, 36(2), 97-112.

Wechsler, D. (1999). Wechsler Abbreviated Scale of Intelligence. San Antonio, TX: The Psychological Corporation.

Wechsler, D. (2011). Wechsler Abbreviated Scale of Intelligence (2nd ed.). Bloomington, $\mathrm{MN}$ : Pearson.

Weems, C. F., Saltzman, K. M., Reiss, A. L., \& Carrion, V. G. (2003). A prospective test of the association between hyperarousal and emotional numbing in youth with a history of traumatic stress. Journal of Clinical Child \& Adolescent Psychology, 32(1), 166-171. doi: 10.1207/S15374424JCCP3201_15

Wei, C., Hoff, A., Villabo, M. A., Peterman, J., Kendall, P. C., Piacentini, J., ... March, J. (2014). Assessing anxiety in youth with the Multidimensional Anxiety Scale for Children (MASC). Journal of Clinical Child and Adolescent Psychology, 43(4), 566-578. doi: 10.1080/15374416.2013.814541

Weyers, P., Mühlberger, A., Kund, A., Hess, U., \& Pauli, P. (2009). Modulation of facial reactions to avatar emotional faces by nonconscious competition priming. Psychophysiology, 46, 328-335. doi: 10.1111/j.1469-8986.2008.00771.x

Woodworth, M., \& Waschbusch, D. (2008). Emotional processing in children with conduct problems and callous-unemotional traits. Child Care and Healthy Development, 34(2), 234-244. 
APPENDICES 

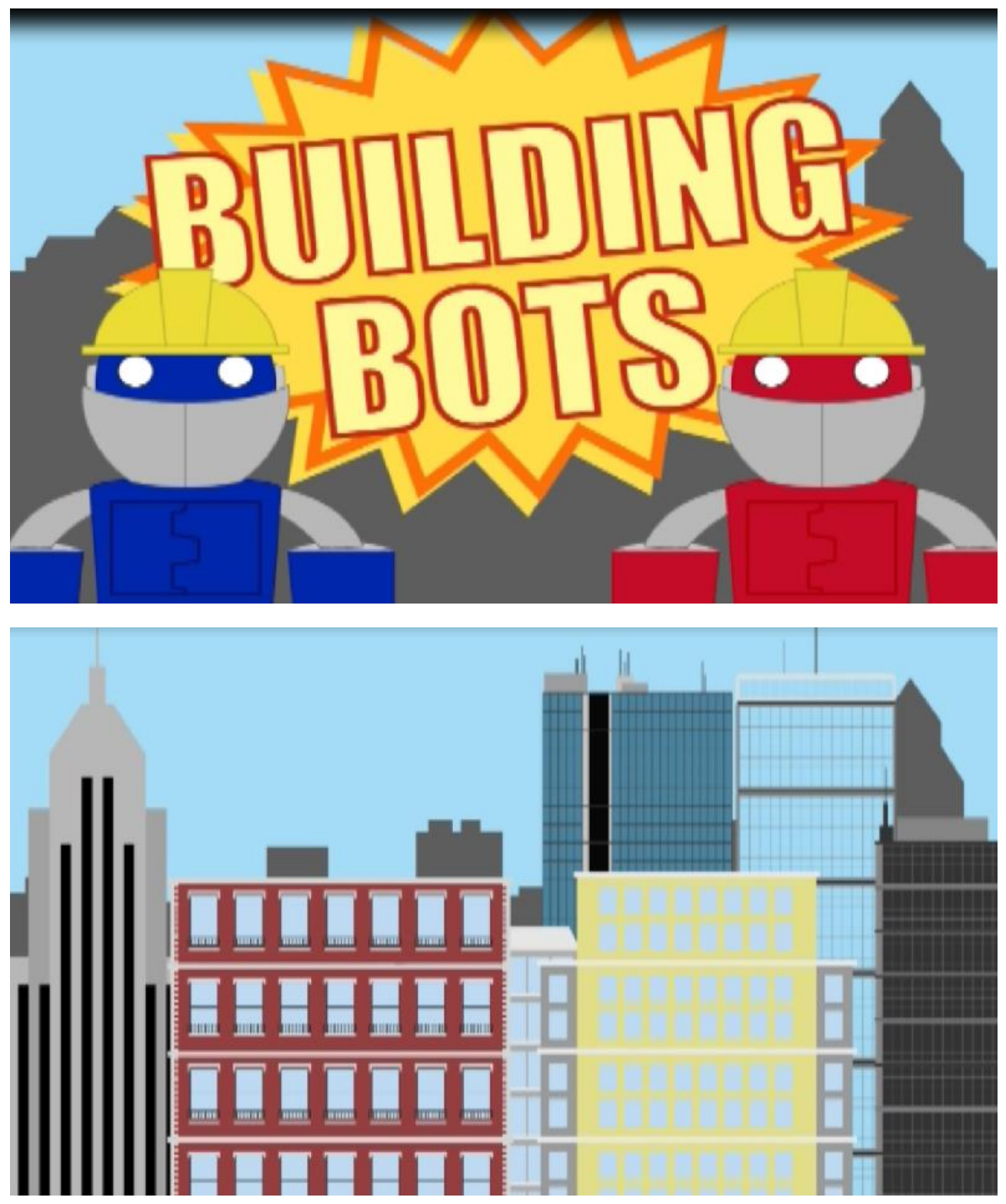

Figure 1. Excerpts from the SuperBuilder game play simulation. Participants were told they were building the red brick skyscraper, while their opponent was building the yellow skyscraper. 


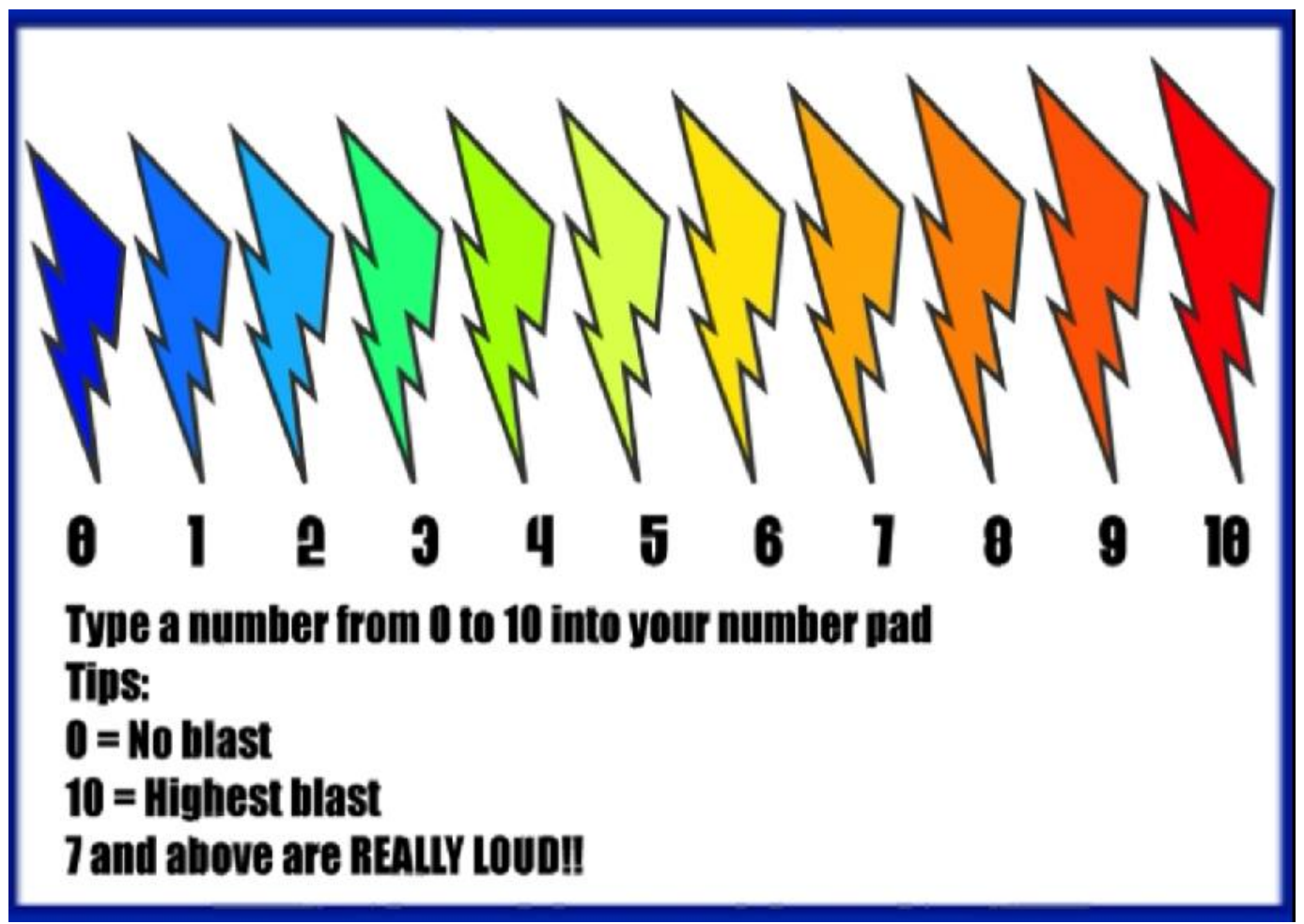

Figure 2. Explanation of SuperBuilder sound blast levels presented to the child participant. 

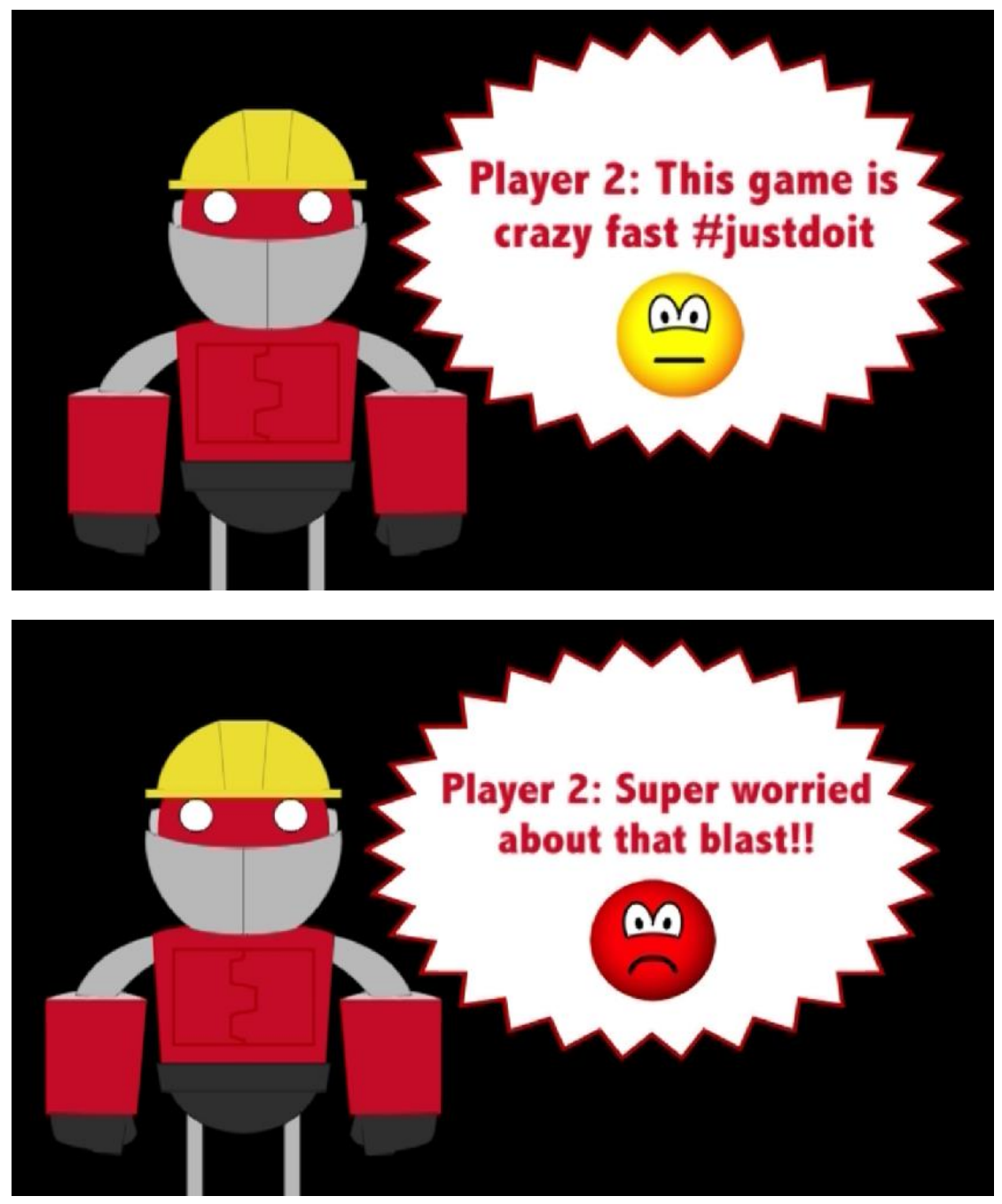

Figure 3. Neutral and distress messages, respectively, sent from the SuperBuilder simulated opponent to the child participant. 
Table 1. Descriptive statistics

\begin{tabular}{|c|c|c|c|}
\hline Child Age & 9.89 & 1.58 & $7-13$ \\
\hline Family Income & 72.19 & 49.60 & $17-200$ \\
\hline Child FSIQ & 107.70 & 13.42 & $64-132$ \\
\hline $\mathrm{RSA}_{\text {Baseline }}$ & 6.65 & 1.23 & $3.67-8.92$ \\
\hline $\mathrm{RSA}_{\text {DistressExposure }}$ & 6.74 & 1.24 & $3.51-9.06$ \\
\hline RSA Distress1 & 6.83 & 1.32 & $2.89-9.33$ \\
\hline $\mathrm{RSA}_{\text {Distress2 }}$ & 6.83 & 1.34 & $3.60-9.37$ \\
\hline $\mathrm{RSA}_{\text {Distress3 }}$ & 6.72 & 1.31 & $3.63-9.07$ \\
\hline RSA Distress4 & 6.69 & 1.34 & $3.16-9.09$ \\
\hline RSA Distress5 & 6.65 & 1.29 & $3.67-9.18$ \\
\hline RSAReactivity & -0.09 & 0.42 & $-0.89-0.90$ \\
\hline MASC & 46.96 & 18.30 & $10-91$ \\
\hline ICU & 8.34 & 5.45 & $0-19$ \\
\hline Aggression-Distress Cue Absent & 8.00 & 2.81 & $0-10$ \\
\hline Aggression-Distress Cue Salient & 7.71 & 3.40 & $0-10$ \\
\hline Aggression-Total & 15.71 & 5.40 & $0-20$ \\
\hline CPSS & 18.87 & 12.32 & $1-51$ \\
\hline
\end{tabular}


Table 2. Zero-order correlations between study variables.

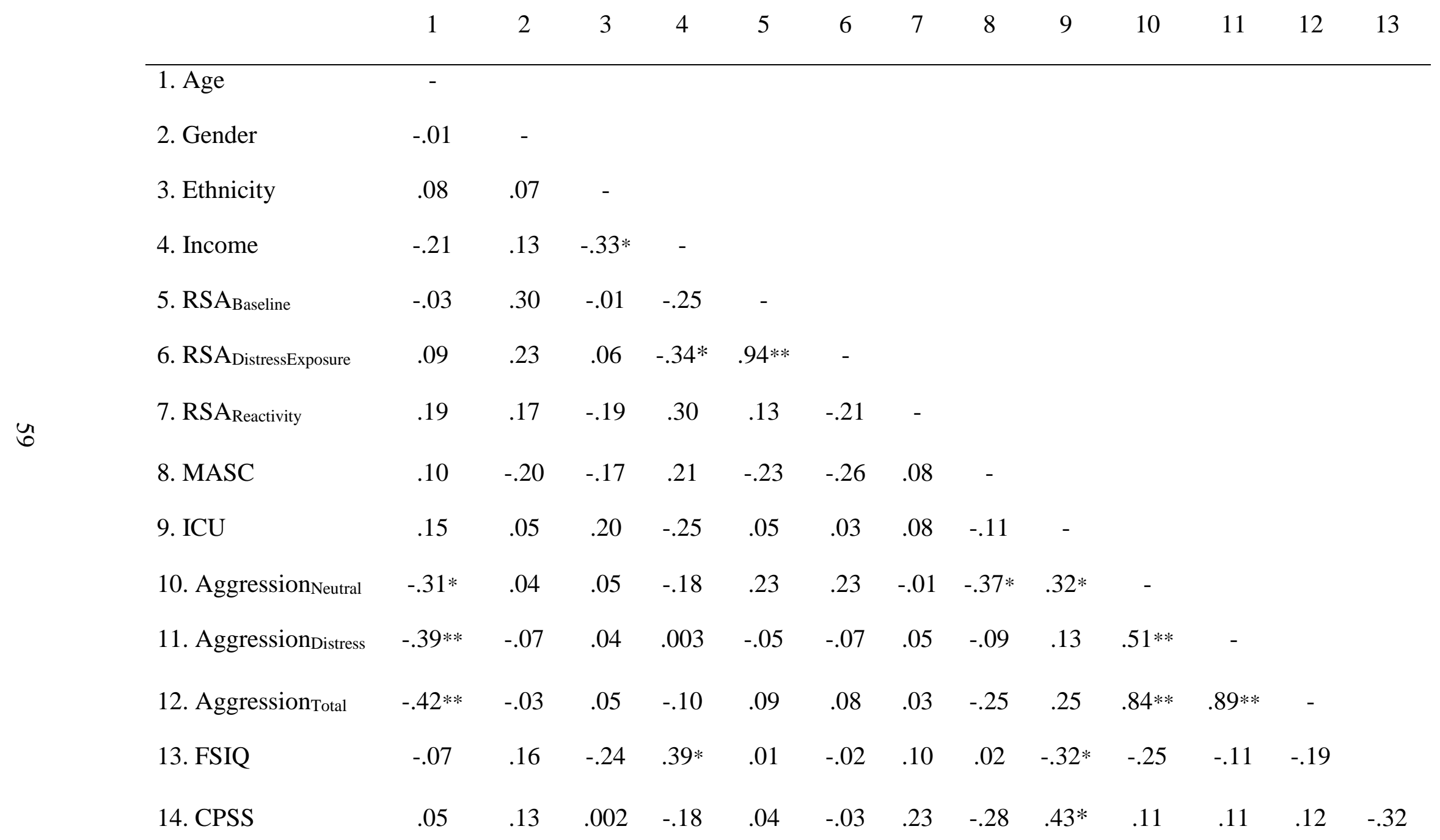


Table 3. Coefficients for the SuperBuilder hierarchical regression models predicting Aggression, with Anxiety as a moderator

\begin{tabular}{|c|c|c|c|c|}
\hline & \multicolumn{4}{|c|}{ Predicting Aggression-Distress Cue Absent } \\
\hline & $\beta$ & SE & LLCI & ULCI \\
\hline MASC & -0.065 & 0.024 & -0.113 & -0.016 \\
\hline ICU & 0.162 & 0.064 & 0.033 & 0.291 \\
\hline \multirow[t]{3}{*}{ MASC x ICU } & 0.011 & 0.005 & 0.001 & 0.022 \\
\hline & \multicolumn{4}{|c|}{ Predicting Aggression-Distress Cue Present } \\
\hline & $\beta$ & SE & LLCI & ULCI \\
\hline MASC & -0.020 & 0.039 & -0.098 & 0.058 \\
\hline ICU & 0.081 & 0.105 & -0.131 & 0.294 \\
\hline \multirow[t]{3}{*}{ MASC x ICU } & 0.006 & 0.009 & -0.012 & 0.024 \\
\hline & \multicolumn{4}{|c|}{ Predicting Aggression-Total } \\
\hline & $\beta$ & SE & LLCI & ULCI \\
\hline MASC & -0.085 & 0.048 & -0.182 & 0.013 \\
\hline ICU & 0.244 & 0.148 & -0.056 & 0.543 \\
\hline MASC x ICU & 0.017 & 0.011 & -0.006 & 0.039 \\
\hline
\end{tabular}

Note: $\beta=$ Beta coefficient; $S E=$ standard error; $L L C I=$ lower limit of $95 \%$ confidence interval; ULCI=upper limit of $95 \%$ confidence interval; MASC=caregiver-rated total anxiety; ICU=caregiver-rated total CU traits. MASC x ICU = interaction between caregiver-rated total anxiety and total CU traits. 
Table 4. Coefficients for the SuperBuilder hierarchical regression models predicting Aggression, with traumatic stress as a moderator

\begin{tabular}{|c|c|c|c|c|}
\hline & \multicolumn{4}{|c|}{ Predicting Aggression_-Distress Cue Absent } \\
\hline & $\beta$ & SE & LLCI & ULCI \\
\hline CPSS & 0.0001 & 0.059 & -0.124 & 0.124 \\
\hline ICU & 0.099 & 0.137 & -0.187 & 0.385 \\
\hline \multirow[t]{3}{*}{ CPSS x ICU } & 0.001 & 0.010 & -0.020 & 0.022 \\
\hline & \multicolumn{4}{|c|}{ Predicting Aggression-Distress Cue Present } \\
\hline & $\beta$ & $\mathrm{SE}$ & LLCI & ULCI \\
\hline CPSS & 0.019 & 0.074 & -0.136 & 0.173 \\
\hline ICU & 0.085 & 0.164 & -0.259 & 0.429 \\
\hline \multirow[t]{3}{*}{ CPSS x ICU } & -0.005 & 0.016 & -0.039 & 0.028 \\
\hline & \multicolumn{4}{|c|}{ Predicting Aggression-Total } \\
\hline & $\beta$ & $\mathrm{SE}$ & LLCI & ULCI \\
\hline CPSS & 0.019 & 0.124 & -0.240 & 0.277 \\
\hline ICU & 0.184 & 0.271 & -0.383 & 0.752 \\
\hline CPSS x ICU & -0.004 & 0.024 & -0.054 & 0.046 \\
\hline
\end{tabular}

Note: $\beta=$ Beta coefficient; $S E=$ standard error; $L L C I=$ lower limit of $95 \%$ confidence interval; ULCI=upper limit of $95 \%$ confidence interval; CPSS=child-rated total traumatic stress; ICU=caregiver-rated total CU traits. CPSS x ICU = interaction between childrated total traumatic stress and total CU traits. 
Table 5. Coefficients for the hierarchical regression models perceptions of simulated opponent's emotions in the absence of a distress cue, with anxiety as a moderator

MASC

Predicting "Calm" Ratings_-Distress Cue Absent

ICU

0.018

SE

LLCI

ULCI

MASC x ICU

0.0002

0.010

$-0.021$

0.020

$-0.001$

0.031

$-0.081$

0.044

MASC

Predicting “Happy” Ratings_-Distress Cue Absent $\beta$

LLCI

ULCI

$\begin{array}{llll}-0.006 & 0.010 & -0.027 & 0.016\end{array}$

ICU

$-0.043$

0.030

$-0.104$

0.018

MASC x ICU

$-0.001$

0.002

$-0.005$

0.003

Predicting "Angry" Ratings_-Distress Cue Absent

MASC

\begin{tabular}{llll}
$\beta$ & SE & LLCI & ULCI \\
\hline 0.013 & 0.008 & -0.002 & 0.029 \\
0.027 & 0.032 & -0.038 & 0.092 \\
-0.001 & 0.002 & -0.005 & 0.002
\end{tabular}

MASC x ICU

Predicting "Sad" Ratings_-Distress Cue Absent

MASC

$$
\beta
$$

SE

LLCI

ULCI

$$
0.007
$$

0.008

$-0.010$

0.023

ICU

0.001

0.026

$-0.052$

0.054

MASC x ICU

$-0.002$

0.002

$-0.006$

0.001 


\begin{tabular}{llccr} 
& \multicolumn{4}{c}{ Predicting "Scared" Ratings- Distress Cue Absent } \\
\cline { 2 - 4 } & $\beta$ & SE & LLCI & ULCI \\
\cline { 2 - 5 } MASC & 0.006 & 0.010 & -0.014 & 0.026 \\
MASC x ICU & 0.015 & 0.035 & -0.057 & 0.087 \\
& 0.001 & 0.002 & -0.004 & 0.005
\end{tabular}

Note: $\beta=$ Beta coefficient; $S E=$ standard error; $L L C I=$ lower limit of $95 \%$ confidence interval; ULCI=upper limit of $95 \%$ confidence interval; MASC=caregiver-rated total anxiety; ICU=caregiver-rated total CU traits. MASC x ICU = interaction between caregiver-rated total anxiety and total CU traits. 
Table 6. Coefficients for the hierarchical regression models perceptions of simulated opponent's emotions in the presence of a distress cue, with anxiety as a moderator

MASC

Predicting “Calm” Ratings_-Distress Cue Present

ICU

MASC x ICU

MASC

$\beta$

SE

LLCI

ULCI

$\begin{array}{llll}0.009 & 0.013 & -0.016 & 0.035\end{array}$

0.070

0.033

0.004

0.137

0.001

0.003

$-0.004$

0.006

Predicting "Happy” Ratings_-Distress Cue Present

$\beta \quad$ SE $\quad$ LLCI ULCI

$\begin{array}{llll}0.008 & 0.010 & -0.012 & 0.027\end{array}$

ICU

0.069

0.030

0.009

0.130

MASC x ICU

0.0004

0.002

$-0.003$

0.004

Predicting “Angry” Ratings_-Distress Cue Present

MASC

\begin{tabular}{llll}
$\beta$ & SE & LLCI & ULCI \\
\hline-0.010 & 0.012 & -0.035 & 0.015 \\
-0.039 & 0.042 & -0.124 & 0.047 \\
-0.003 & 0.002 & -0.008 & 0.001
\end{tabular}

MASC x ICU

Predicting "Sad” Ratings—Distress Cue Present

ICU

$\beta \quad S$

MASC

$$
0.006
$$

SE

LLCI

ULCI

ICU

0.009

0.047

0.103

MASC x ICU

$-0.001$

0.004

$-0.008$

0.007 


\begin{tabular}{llccc} 
& \multicolumn{4}{c}{ Predicting "Scared" Ratings-Distress Cue Present } \\
\cline { 2 - 5 } & $\beta$ & SE & LLCI & ULCI \\
\cline { 2 - 5 } MASC & -0.0003 & 0.014 & -0.029 & 0.029 \\
MASC x ICU & -0.064 & 0.030 & -0.125 & -0.003 \\
MAS & 0.001 & 0.003 & -0.005 & 0.007
\end{tabular}

Note: $\beta=$ Beta coefficient; $S E=$ standard error; $L L C I=$ lower limit of $95 \%$ confidence interval; ULCI=upper limit of $95 \%$ confidence interval; MASC $=$ caregiver-rated total anxiety; ICU=caregiver-rated total CU traits. MASC x ICU = interaction between caregiver-rated total anxiety and total CU traits. 
Table 7. Coefficients for the hierarchical regression models predicting changes in perceptions of simulated opponent's emotions, with anxiety as a moderator

Predicting Change in "Calm" Ratings

MASC

SE

LLCI

ULCI

$\beta$

\begin{tabular}{llll}
\hline-0.010 & 0.016 & -0.042 & 0.022
\end{tabular}

ICU

$-0.088$

0.052

$-0.192$

0.017

MASC x ICU

$-0.001$

0.003

$-0.007$

0.005

Predicting Change in "Happy" Ratings

MASC

\begin{tabular}{llll}
$\beta$ & SE & LLCI & ULCI \\
\hline-0.013 & 0.012 & -0.037 & 0.011
\end{tabular}

ICU

$-0.112$

0.037

$-0.188$

0.037

MASC x ICU

$-0.001$

0.002

$-0.005$

0.003

Predicting Change in "Angry" Ratings

MASC

$$
\beta
$$

SE

LLCI

ULCI

0.024

0.014

$-0.005$

0.052

ICU

0.066

0.037

$-0.009$

0.142

MASC x ICU

0.002

0.002

$-0.003$

0.007

Predicting Change in "Sad" Ratings

MASC

\begin{tabular}{llll}
$\beta$ & SE & LLCI & ULCI \\
\hline 0.0002 & 0.018 & -0.035 & 0.036
\end{tabular}

ICU

$-0.008$

0.052

$-0.112$

0.097

MASC x ICU

$-0.001$

0.005

$-0.011$

0.008 


\section{Predicting Change in "Scared" Ratings}

\begin{tabular}{lllll} 
& $\beta$ & SE & LLCI & ULCI \\
\cline { 2 - 5 } MASC & 0.007 & 0.019 & -0.031 & 0.044 \\
ICU & 0.079 & 0.054 & -0.031 & 0.189 \\
MASC x ICU & -0.0003 & 0.004 & -0.008 & 0.007
\end{tabular}

Note: $\beta=$ Beta coefficient; $\mathrm{SE}=$ standard error; $\mathrm{LLCI}=$ lower limit of $95 \%$ confidence interval; ULCI=upper limit of $95 \%$ confidence interval; MASC=caregiver-rated total anxiety; ICU=caregiver-rated total CU traits. MASC x ICU = interaction between caregiver-rated total anxiety and total CU traits. 
Table 8. Coefficients for the hierarchical regression models perceptions of simulated opponent's emotions in the absence of a distress cue, with traumatic stress as a moderator

CPSS

ICU

CPSS x ICU

CPSS

ICU

CPSS x ICU

CPSS

ICU

CPSS x ICU

CPSS

ICU

CPSS x ICU

Predicting “Calm” Ratings_-Distress Cue Absent

\begin{tabular}{llll}
$\beta$ & SE & LLCI & ULCI \\
\hline-0.017 & 0.032 & -0.084 & 0.050 \\
0.043 & 0.072 & -0.109 & 0.194 \\
-0.001 & 0.006 & -0.014 & 0.011
\end{tabular}

Predicting “Happy” Ratings_-Distress Cue Absent

\begin{tabular}{llll}
$\beta$ & SE & LLCI & ULCI \\
\hline 0.014 & 0.026 & -0.041 & 0.067 \\
-0.059 & 0.065 & -0.196 & 0.078 \\
0.002 & 0.008 & -0.015 & 0.018
\end{tabular}

Predicting “Angry” Ratings_-Distress Cue Absent

\begin{tabular}{llll}
$\beta$ & SE & LLCI & ULCI \\
\hline 0.020 & 0.038 & -0.060 & 0.100 \\
0.043 & 0.071 & -0.106 & 0.193 \\
0.002 & 0.013 & -0.026 & 0.030
\end{tabular}

Predicting "Sad” Ratings_-Distress Cue Absent

$\beta \quad$ SE $\quad$ LLCI ULCI

\begin{tabular}{llll}
\hline 0.027 & .027 & 0.332 & -0.030 \\
-0.005 & 0.050 & 0.929 & -0.110 \\
-0.003 & 0.008 & 0.735 & -0.019
\end{tabular}




\begin{tabular}{lcccc} 
& \multicolumn{4}{c}{ Predicting "Scared" Ratings- Distress Cue Absent } \\
& $\beta$ & SE & LLCI & ULCI \\
\cline { 2 - 5 } CPSS & -0.007 & 0.033 & 0.846 & -0.077 \\
ICU & 0.063 & 0.073 & 0.404 & -0.091 \\
CPSS x ICU & 0.003 & 0.012 & 0.803 & -0.022
\end{tabular}

Note: $\beta=$ Beta coefficient; $S E=$ standard error; $L L C I=$ lower limit of $95 \%$ confidence interval; ULCI=upper limit of $95 \%$ confidence interval; $\mathrm{CPSS}=$ child-rated total anxiety; ICU=caregiver-rated total CU traits. CPSS x ICU = interaction between child-rated total traumatic stress and caregiver-rated total CU traits. 
Table 9. Coefficients for the hierarchical regression models perceptions of simulated opponent's emotions in the presence of a distress cue, with traumatic stress as a moderator

CPSS

$\mathrm{ICU}$

CPSS x ICU

CPSS

ICU

CPSS x ICU

CPSS

ICU

CPSS x ICU

CPSS

ICU

CPSS x ICU

Predicting "Calm" Ratings_-Distress Cue Present

\begin{tabular}{llcc}
$\beta$ & SE & LLCI & ULCI \\
\hline-0.058 & 0.030 & -0.121 & 0.006
\end{tabular}

0.165

0.048

0.064

0.266

0.009

0.005

$-0.002$

0.019

Predicting "Happy" Ratings_-Distress Cue Present

\begin{tabular}{llcc}
$\beta$ & SE & LLCI & ULCI \\
\hline 0.003 & 0.028 & -0.056 & 0.062
\end{tabular}

0.069

0.057

$-0.050$

0.189

$-0.001$

0.005

$-0.011$

0.009

Predicting “Angry” Ratings_-Distress Cue Present

\begin{tabular}{llll}
$\beta$ & SE & LLCI & ULCI \\
\hline 0.034 & 0.031 & -0.031 & 0.010 \\
-0.005 & 0.075 & -0.161 & 0.152 \\
0.002 & 0.008 & -0.016 & 0.019
\end{tabular}

Predicting "Sad” Ratings_-Distress Cue Present

$\beta \quad$ SE $\quad$ LLCI $\quad$ ULCI

\begin{tabular}{llll}
\hline 0.012 & 0.038 & -0.067 & 0.091 \\
0.023 & 0.086 & -0.158 & 0.203 \\
0.005 & 0.0007 & -0.010 & 0.019
\end{tabular}




\begin{tabular}{lcccc} 
& \multicolumn{4}{c}{ Predicting "Scared" Ratings- Distress Cue Present } \\
\cline { 2 - 4 } & $\beta$ & SE & LLCI & ULCI \\
\cline { 2 - 4 } CPSS & 0.073 & 0.023 & 0.024 & 0.121 \\
ICU & -0.136 & 0.056 & -0.254 & -0.018 \\
CPSS x ICU & -0.005 & 0.007 & -0.020 & 0.011
\end{tabular}

Note: $\beta=$ Beta coefficient; $S E=$ standard error; $L L C I=$ lower limit of $95 \%$ confidence interval; ULCI=upper limit of $95 \%$ confidence interval; CPSS=child-rated total anxiety; ICU=caregiver-rated total CU traits. CPSS x ICU = interaction between child-rated total traumatic stress and caregiver-rated total CU traits. 
Table 10. Coefficients for the hierarchical regression models predicting changes in perceptions of simulated opponent's emotions, with traumatic stress as a moderator

$$
\text { Predicting Change in "Calm” Ratings }
$$

CPSS

ICU

CPSS x ICU

CPSS

ICU

CPSS x ICU

CPSS

ICU

CPSS x ICU

CPSS

ICU

CPSS x ICU
SE

LLCI

$-0.033$

$-0.362$

$-0.031$

0.010

Predicting Change in "Happy” Ratings

$\beta$

SE

LLCI

ULCI

0.010

$-0.128$

0.064

$-0.263$

0.006

0.003

0.006

$-0.010$

0.016

Predicting Change in "Angry" Ratings

\begin{tabular}{llll}
$\beta$ & SE & LLCI & ULCI \\
\hline-0.014 & 0.035 & -0.088 & 0.059
\end{tabular}

0.048

0.066

$-0.090$

0.186

0.001

0.008

$-0.016$

0.017

Predicting Change in "Sad" Ratings

\begin{tabular}{llcc}
$\beta$ & SE & LLCI & ULCI \\
\hline 0.015 & 0.048 & -0.087 & 0.116
\end{tabular}

$-0.027$

0.107

$-0.252$

0.198

$-0.007$

0.012

$-0.033$

0.019 
Predicting Change in "Scared" Ratings

\begin{tabular}{lllll} 
& \multicolumn{1}{l}{$\beta$} & SE & LLCI & ULCI \\
\cline { 2 - 5 } CPSS & -0.079 & 0.052 & 0.030 & -0.189 \\
ICU & 0.199 & 0.116 & -0.045 & 0.442 \\
CPSS x ICU & 0.008 & 0.019 & -0.033 & 0.048
\end{tabular}

Note: $\beta=$ Beta coefficient; $S E=$ standard error; LLCI=lower limit of $95 \%$ confidence interval; ULCI=upper limit of $95 \%$ confidence interval; CPSS=child-rated traumatic stress; ICU=caregiver-rated total CU traits; CPSS x ICU= interaction between child-rated total traumatic stress and caregiver-rated total $\mathrm{CU}$ traits. 
Table 11. Coefficients for hierarchical regression models predicting parasympathetic responses, with anxiety as a moderator

\begin{tabular}{lllcc} 
& \multicolumn{4}{c}{ Predicting RSAResting } \\
\cline { 2 - 4 } MASC & $\beta$ & SE & LLCI & ULCI \\
\cline { 2 - 5 } ICU & -0.019 & 0.012 & -0.044 & 0.007 \\
MASC x ICU & 0.010 & 0.037 & -0.065 & 0.085 \\
& 0.003 & 0.003 & -0.003 & 0.009 \\
MASC & $\beta$ & Predicting RSAReactivity & \\
ICU & 0.003 & SE & LLCI & ULCI \\
MASC x ICU & 0.006 & 0.004 & -0.006 & 0.011 \\
& -0.001 & 0.001 & -0.014 & 0.026 \\
& & & -0.002 & 0.001
\end{tabular}

Note: Note: $\beta=$ Beta coefficient; SE=standard error; LLCI=lower limit of $95 \%$ confidence interval; ULCI=upper limit of $95 \%$ confidence interval; MASC $=$ caregiver-rated total anxiety; ICU=caregiver-rated total CU traits; MASC x ICU = interaction between caregiver-rated total anxiety and total CU traits; RSA = respiratory sinus arrhythmia. 
Table 12. Coefficients for HLM predicting RSA Distress $s$ scores across time, with CU and anxiety as moderators

\begin{tabular}{|c|c|c|c|c|}
\hline & \multicolumn{4}{|c|}{$\mathrm{RSA}_{\text {Distress }}$} \\
\hline & $\mathrm{B}$ & SE & $t(215)$ & $p$ \\
\hline $\mathrm{RSA}_{\text {Resting }}$ & 0.936 & 0.035 & 27.064 & $<.001$ \\
\hline Time & -0.046 & 0.029 & -1.605 & .110 \\
\hline MASC & 0.006 & 0.005 & 1.194 & .234 \\
\hline $\mathrm{ICU}$ & 0.021 & 0.018 & 1.186 & .237 \\
\hline Time $\mathrm{x}$ ICU & -0.009 & 0.005 & -1.676 & .095 \\
\hline Time $\mathrm{x}$ MASC & -0.003 & 0.002 & -2.138 & .034 \\
\hline Time x ICUxMASC & 0.0003 & 0.0001 & 1.793 & .074 \\
\hline
\end{tabular}

Note: Note: $\mathrm{B}=$ coefficient estimate; $\mathrm{SE}=$ standard error; MASC=caregiver-rated anxiety; ICU=caregiver-rated total CU traits; MASC x ICU= interaction between caregiver-rated total anxiety and caregiver-rated total CU traits; Time $\mathrm{x}$ ICUxMASC=interaction between time and the product term of caregiver-rated total anxiety and caregiver-rated total CU traits; RSA = respiratory sinus arrhythmia. 
Table 13. Coefficients for hierarchical regression models predicting parasympathetic responses, with traumatic stress as a moderator

\begin{tabular}{|c|c|c|c|c|}
\hline & \multicolumn{4}{|c|}{$\mathrm{RSA}_{\text {Resting }}$} \\
\hline & $\beta$ & $\mathrm{SE}$ & LLCI & ULCI \\
\hline CPSS & 0.015 & 0.025 & -0.039 & 0.068 \\
\hline ICU & -0.036 & 0.068 & -0.179 & 0.107 \\
\hline \multirow[t]{3}{*}{ CPSS x ICU } & -0.003 & 0.005 & -0.014 & 0.008 \\
\hline & \multicolumn{4}{|c|}{$\mathrm{RSA}_{\text {Reactivity }}$} \\
\hline & $\beta$ & SE & LLCI & ULCI \\
\hline CPSS & 0.008 & 0.012 & -0.017 & 0.032 \\
\hline ICU & 0.001 & 0.023 & -0.047 & 0.048 \\
\hline CPSS x ICU & $<.001$ & 0.002 & -0.004 & 0.004 \\
\hline
\end{tabular}

Note: $\beta=$ Beta coefficient; $S E=$ standard error; LLCI=lower limit of $95 \%$ confidence interval; ULCI=upper limit of $95 \%$ confidence interval; CPSS=child-rated traumatic stress; ICU=caregiver-rated total CU traits; CPSS x ICU= interaction between child-rated total traumatic stress and caregiver-rated total $\mathrm{CU}$ traits; RSA = respiratory sinus arrhythmia. 
Table 14. Coefficients for HLM predicting RSADistress across time, with CU and traumatic stress as moderators

\begin{tabular}{lcccc} 
& \multicolumn{5}{c}{ Predicting RSA } & \\
& $\mathrm{B}$ & $\mathrm{SE}$ & $t(115)$ & $p$ \\
RSA & & & & \\
Timesting & 0.867 & .037 & 23.196 & $<.001$ \\
CPSS & -0.043 & 0.037 & -1.178 & .241 \\
ICU & 0.009 & 0.011 & 0.863 & .390 \\
Time x ICU & -0.011 & 0.024 & -0.447 & .656 \\
Time x CPSS & 0.001 & 0.007 & 0.134 & .893 \\
Time x ICUxCPSS & -0.004 & 0.003 & -1.320 & .189
\end{tabular}

Note: $\beta=$ Beta coefficient; $S E=$ standard error; LLCI=lower limit of $95 \%$ confidence interval; ULCI=upper limit of $95 \%$ confidence interval; CPSS=child-rated traumatic stress; ICU=caregiver-rated total CU traits; CPSS x ICU= child-rated total traumatic stress and interaction between caregiver-rated total CU traits; Time $\mathrm{x}$ ICUxCPSS=interaction between time and product term of caregiver-rated total CU traits and child-rated total traumatic stress; RSA=respiratory sinus arrhythmia. 
Aim I/b.

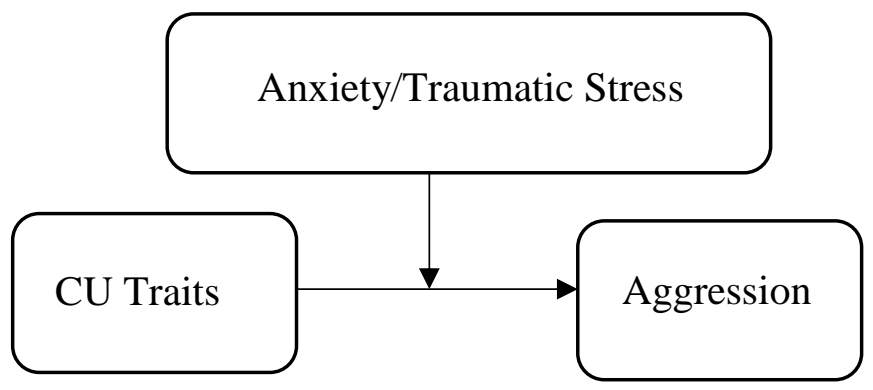

Aim II/b.
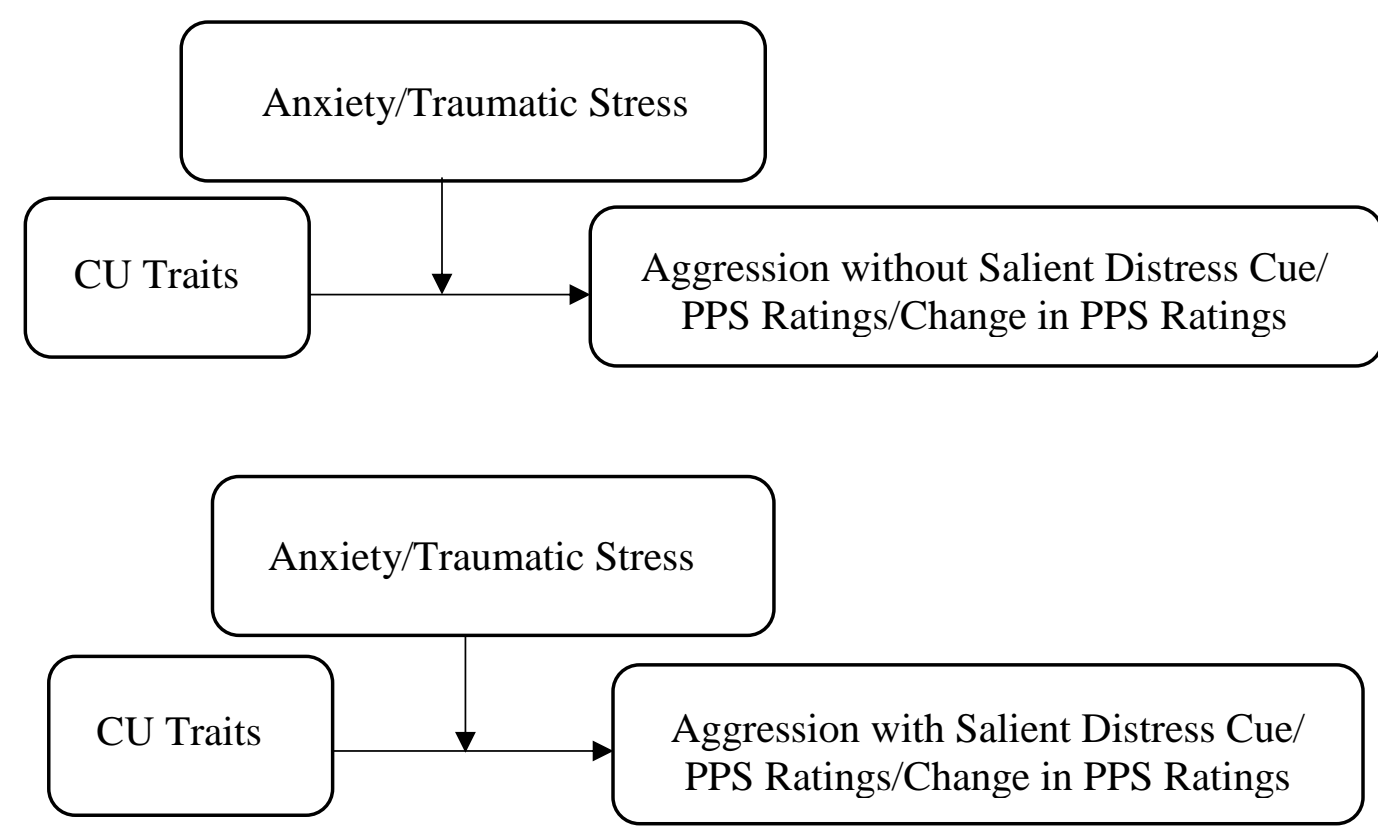

Aim III/b.

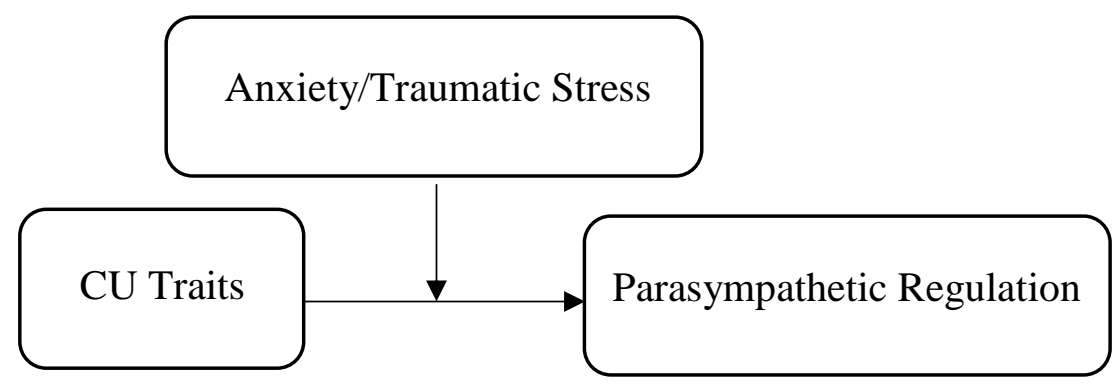

Figure 4. Visual depiction of statistical models. 


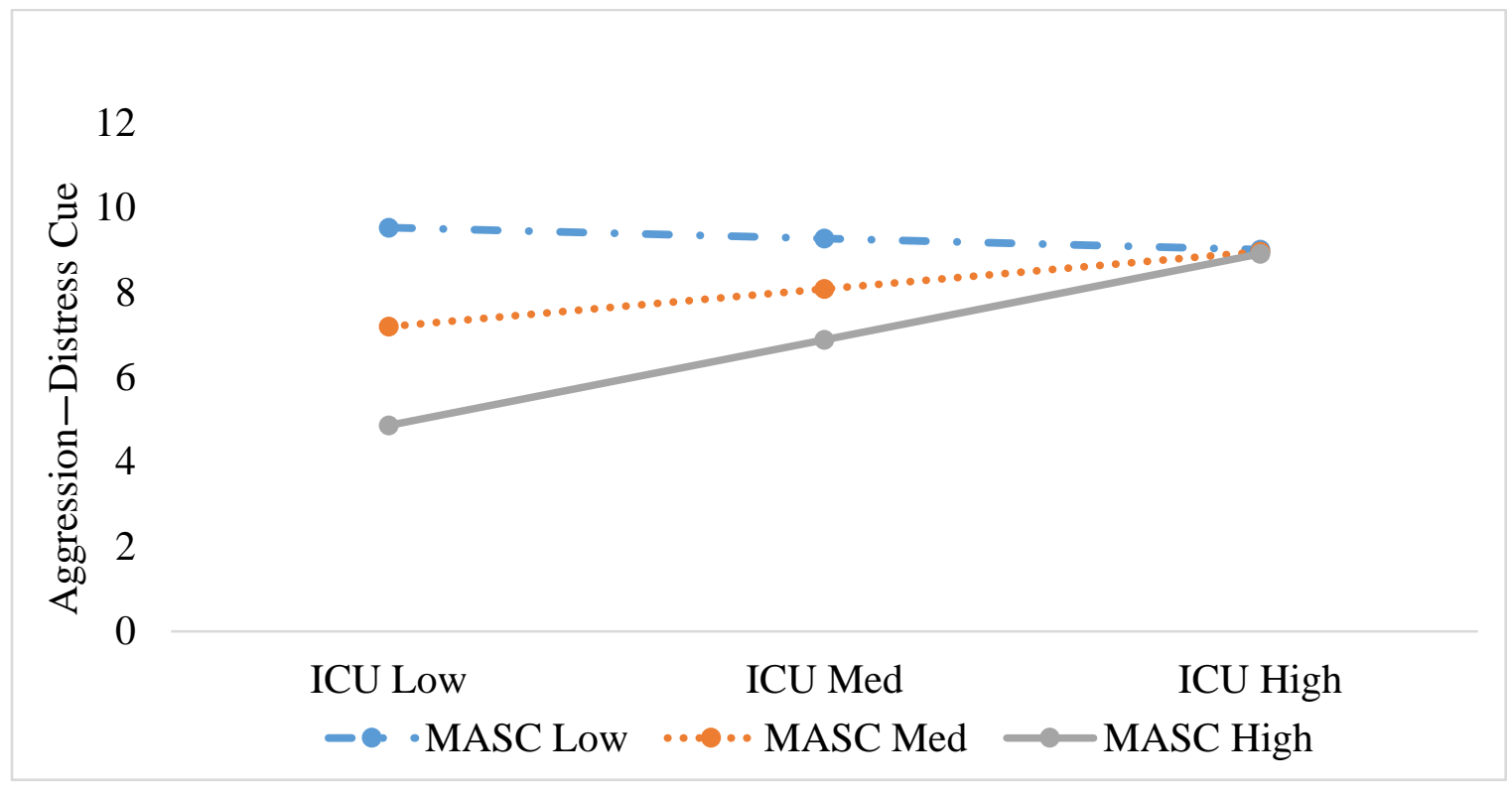

Figure 5. Graph depicting the interactive relationship between CU and anxiety when predicting aggression in the absence of a distress cue. 


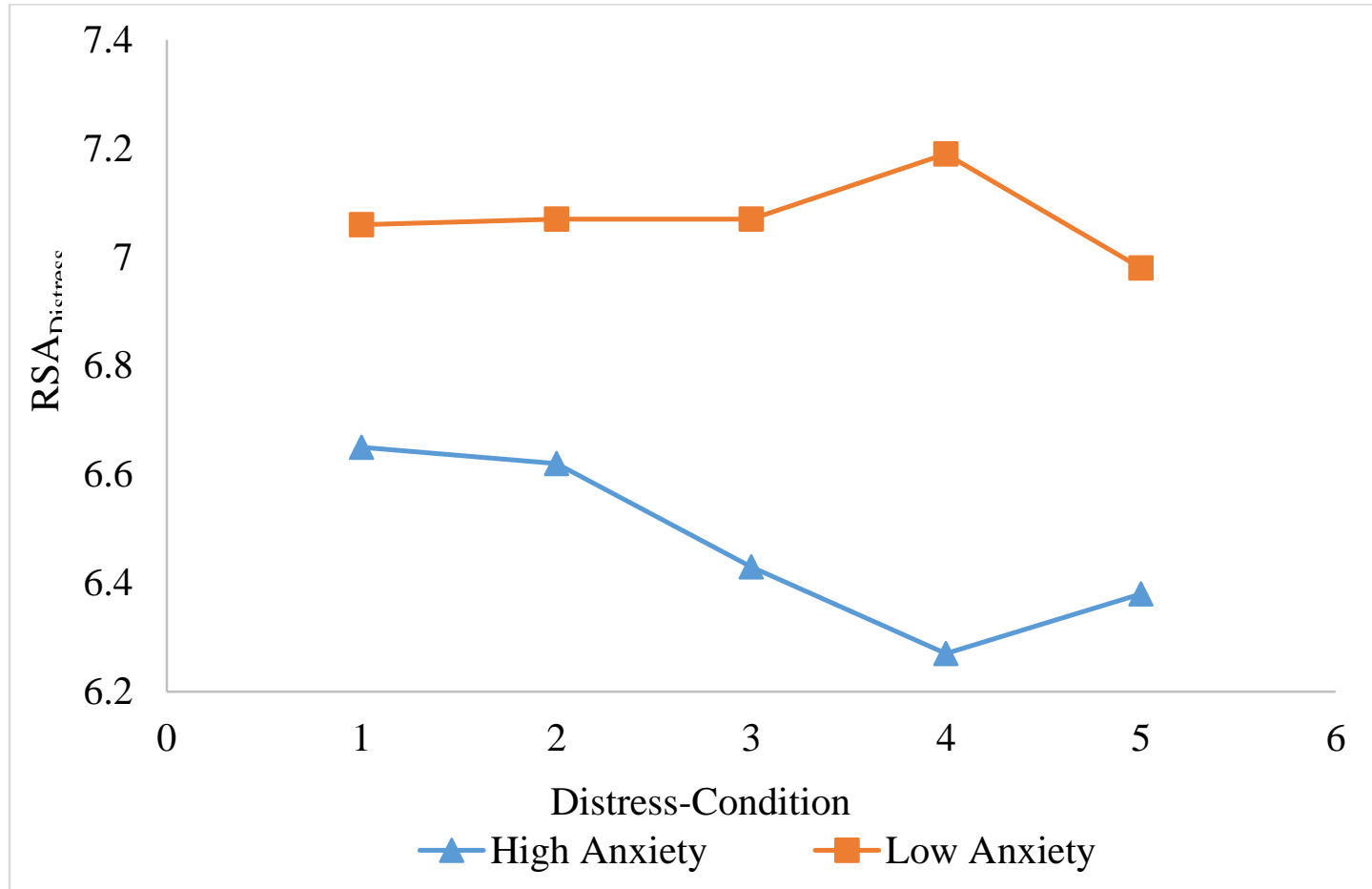

Figure 6. Graph depicting the relationships between respiratory sinus arrhythmia and caregiver-reported child anxiety scores on the MASC across the five distress-condition epochs in the Distress Response task. 
VITA

\section{KATHLEEN ISABEL CRUM}

2005-2009

B.A., Psychology, Honors College, Summa Cum Laude Florida International University

Miami, Florida

2009

National Institute of Health Travel Award

2010-2014

M.S., Psychology

Florida International University

Miami, Florida

2010-2016

Graduate Assistant

Florida International University

Miami, Florida

$2013 \& 2014$

2014

2014-2016

2015

2015-2016
Award for Distinguished Poster Contribution

Elizabeth Munsterberg Koppitz Graduate Student

Fellowship in Child Psychology

Doctoral Candidate

Florida International University

Miami, Florida

Student Research Award Competition Honorable Mention

Clinical Intern

Medical University of South Carolina

Charleston, South Carolina

\section{SELECTED PUBLICATIONS}

Babinski, D.E., Waxmonsky, J.G., Waschbusch, D.A., Humphrey, H., Alfonso, A., Crum, K.I.,...Pelham, W.E. (2014). A pilot study of stimulant medication for adults with ADHD who are parents of adolescents with ADHD: the acute effects of stimulant medication on observed parent-adolescent interactions. Journal of Child and Adolescent Psychopharmacology, 24(10), 582-585.

Detweiler, M. F., Comer, J. S., Crum, K. I., \& Albano, A. M. (2014). Social anxiety in children and adolescents: Biological, developmental, and social considerations. In S. G. Hofmann, \& P. M. DiBartolo (Eds.), From social anxiety to social phobia: Multiple perspectives (3rd ed.). Boston, MA: Allyn and Bacon. 
Miller, N.V., Haas, S. M., Waschbusch, D. A., Willoughby, M. T., Helseth, S. A., Crum, K. I., Coles, E. K., \& Pelham, W. E., Jr. (2014). Behavior therapy and callous-

unemotional traits: Effects of a pilot study examining modified behavioral contingencies on child behavior. Behavior Therapy, 45(5), 606-618.

Waxmonsky, J. G., Waschbusch, D. A., Babinski, D. E., Humphrey, H. H., Alfonso, A., Crum, K.I., Bernstein, M., Slavec, J., Augustus, J. N., \& Pelham, W. E. (2014). Does pharmacological treatment of ADHD in adults enhance parenting performance? Results of a double-blind, randomized trial. CNS Drugs, 28(7), 665-677.

Chou, P., Cornacchio, D., Cooper-Vince, C., Crum, K. I., \& Comer, J. S. (2015). DSM-5 and the assessment of childhood anxiety disorders: Meaningful progress, new problems, or persistent diagnostic quagmires? Psychopathology Review, 2(1), 30-51.

Crum, K. I., \& Comer, J. S. (2015). Using synchronous videoconferencing to deliver family-based mental health care. Journal of Child and Adolescent Psychopharmacology, 26(3), 229-234.

Crum, K. I., Cornacchio, D., Greif Green, J., Coxe, S., \& Comer, J. S. (2015). Conduct problems among youth exposed to the Boston Marathon attack: The moderating role of violent crime exposure. Journal of Clinical Child and Adolescent Psychology. (Online.)

Crum, K. I., Waschbusch, D. A., Bagner, D., \& Coxe, S. (2015). Effects of callousunemotional traits on the association between parenting and child conduct problems. Child Psychiatry and Human Development, 46(6), 967-980.

Cornacchio, D., Crum, K. I., Coxe, S., Pincus, D. B., \& Comer, J. S. (2016). Irritability and severity of anxious symptomatology among youth with anxiety disorders. Journal of the American Academy of Child and Adolescent Psychiatry, 55(1), 54-61.

Crum, K. I., Waschbusch, D. A., \& Willoughby, M. T. (2016). Callous-unemotional traits influence the nature of the student-teacher relationship and its association with long-term outcomes. Journal of Emotional and Behavioral Disorders, 24, 16-29.

Waschbusch, D. A., Willoughby, M. T., Haas, S. M., Helseth, S. A., Crum, K. I., Altszuler, A. R., Ross, J. M., Coles, E. K., \& Pelham Jr., W. E. (in press). Effects of behavioral treatment modified to fit the learning style of children with conduct problems and callous-unemotional (CU) traits. Journal of Consulting and Clinical Psychology.

Crum, K. I., Cornacchio, D., Coxe, S., Greif Green, J., \& Comer, J. S. (accepted). The cooccurrence of posttraumatic stress and conduct problems following the Boston Marathon bombing: A latent profile analysis. Journal of Traumatic Stress. 